\title{
A review of approaches to estimate wildfire plume injection height within large-scale atmospheric chemical transport models
}

\author{
R. Paugam ${ }^{1}$, M. Wooster ${ }^{1}$, S. Freitas ${ }^{2}$, and M. Val Martin ${ }^{3,4}$ \\ ${ }^{1}$ Kings College London, London, UK \\ ${ }^{2}$ Center for Weather Forecasting and Climate Studies, INPE, Cachoeira Paulista, Brazil \\ ${ }^{3}$ Atmospheric Science Department, Colorado State University, Fort Collins, CO, USA \\ ${ }^{4}$ Chemical and Biological Engineering Department, The University of Sheffield, Sheffield, UK \\ Correspondence to: R. Paugam (ronan.paugam@kcl.ac.uk)
}

Received: 20 January 2015 - Published in Atmos. Chem. Phys. Discuss.: 31 March 2015

Revised: 30 September 2015 - Accepted: 16 October 2015 - Published: 26 January 2016

\begin{abstract}
Landscape fires produce smoke containing a very wide variety of chemical species, both gases and aerosols. For larger, more intense fires that produce the greatest amounts of emissions per unit time, the smoke tends initially to be transported vertically or semi-vertically close by the source region, driven by the intense heat and convective energy released by the burning vegetation. The column of hot smoke rapidly entrains cooler ambient air, forming a rising plume within which the fire emissions are transported. The characteristics of this plume, and in particular the height to which it rises before releasing the majority of the smoke burden into the wider atmosphere, are important in terms of how the fire emissions are ultimately transported, since for example winds at different altitudes may be quite different. This difference in atmospheric transport then may also affect the longevity, chemical conversion, and fate of the plumes chemical constituents, with for example very high plume injection heights being associated with extreme long-range atmospheric transport. Here we review how such landscape-scale fire smoke plume injection heights are represented in largerscale atmospheric transport models aiming to represent the impacts of wildfire emissions on component of the Earth system. In particular we detail (i) satellite Earth observation data sets capable of being used to remotely assess wildfire plume height distributions and (ii) the driving characteristics of the causal fires. We also discuss both the physical mechanisms and dynamics taking place in fire plumes and investigate the efficiency and limitations of currently available injection height parameterizations. Finally, we conclude by suggesting some future parameterization developments and
\end{abstract}

ideas on Earth observation data selection that may be relevant to the instigation of enhanced methodologies aimed at injection height representation.

\section{Introduction}

Biomass burning is a major dynamic of the Earth system (Bowman et al., 2009) responsible for the emission of massive quantities of trace gases and aerosols to the atmosphere (e.g. Andreae and Merlet, 2001; van der Werf et al., 2010). To understand and quantify the effects of these biomass burning emissions on atmospheric composition, air quality, weather, and climate, many fire emission inventories have been developed at scales such as individual areas, countries or regions (e.g. Sestak et al., 2002), continents (e.g. Turquety et al., 2007; Longo et al., 2010), or the entire globe (e.g. FLAMBE (Naval Research Laboratory), GFED (G. van der Wref, VU University Amsterdam), FINN (National Center for Atmospheric Research, NCAR), GFAS (European Center for Medium-range Weather Forecast, ECMWF)) (Reid et al., 2009; van der Werf et al., 2010; Wiedinmyer et al., 2011; Kaiser et al., 2012, respectively).

The use of satellite Earth observation (EO) data is generally considered to be critical to providing the temporal coverage, spatial sampling frequency, and directly observable parameters necessary for creating these inventories, particularly so since landscape fires are highly variable emissions sources, and the exact amounts of material released by the combustion process is highly variable in both space and time 
(Giglio et al., 2006; van der Werf et al., 2010; Kaiser et al., 2012).

When a landscape fire occurs, a rising plume created from the intense heat and convection produced by the energy released by burning vegetation interacts with the ambient atmosphere and transports the smoke emissions, affecting their longevity, chemical conversion, and fate (Freitas et al., 2006). This makes the manner in which the fire emissions are injected into the atmosphere highly variable and sensitive to the smoke plume dynamics. To follow the terminology commonly used in the literature (e.g. Kaiser et al., 2012), when not specified, the term "fire emission" refers to the gaseous and aerosols emissions only and not the heat fluxes (e.g. radiation) emitted by the fire.

Figure 1 shows EO satellite views of the evolution of the smoke plume generated by the "county fire", which occurred in Ocala National Forest (Florida) in 2012. The fire was active from 5 to 13 April 2012 and burned across nearly 14000 hectares $\left(140 \mathrm{~km}^{2}\right)$ of land. The apparent intensity and direction of travel of the smoke plume changes every day, and such variability is most likely related to both changes in the fire activity (for the former) and the local ambient atmospheric conditions (for the later). Together the fire and ambient atmospheric characteristics are the main drivers of the plume dynamics and therefore ultimately of the smoke emissions transport.

In addition to the use of in situ measurements (e.g. Johnson et al., 2008) and satellite Earth observation (e.g. Wooster et al., 2012b), the wide-ranging controls on and impacts of landscape-scale fire emissions can be investigated using atmospheric chemistry transport models (CTMs) (e.g. Colarco et al., 2004; Turquety et al., 2007; Pfister et al., 2011). Such models require information on the quantity and timing of the fire emissions, as well as their chemical makeup, and these generally come from the aforementioned emissions inventories. However, for a more complete representation of the source fires, many CTMs can also make use of information on the altitude at which the bulk of the emitted species is injected into the wider atmosphere, where they can fully interact with ambient atmospheric circulation. In a recent study on fire emission transport Gonzi et al. (2015) use the GEOS-Chem CTM with a horizontal resolution of $2^{\circ} \times 2.5^{\circ}$ and $47 \sigma$ levels forming a vertical stretched mesh with a resolution of $150-200 \mathrm{~m}$ near the planetary boundary layer (PBL). Since at these resolutions we cannot resolve the plume dynamics ( $\lesssim 100 \mathrm{~m}$ Trentmann et al., 2006), parameterizations are therefore required to represent these "smoke plume injection heights" (InjH). The aim of this paper is to review the different approaches required for providing these parameterizations. The paper is structured as follows. First, Sect. 2 provides the background detail on fire plume observations and modelling in large-scale CTMs. The main physical mechanisms responsible for the fire plume dynamics are discussed in Sect. 3. The primary satellite EO data used currently to study plume injection height properties are detailed in Sect. 4. Then, the currently available injection height models and their implementations are discussed in Sect. 5. Finally, a summary and suggestions for further developments in this area are provided in Sect. 6.

\section{Introduction to landscape fire plume observations and modelling}

Fire emissions are a particular case of emissions to the atmosphere, since they can be injected into the atmosphere far above the PBL and can thus potentially spread over a long distance according to local atmospheric circulation patterns. Only emissions from aircraft traffic (Paugam et al., 2010) and volcanoes (Woods, 1995), which are also coupled with intense dynamical mechanisms, offer a similar capability.

The question of the impact of fire emission injection in the atmosphere was first introduced by Chatfield and Delany (1990) and was later extensively reported in EO data. For example, injections of gases and aerosols emitted from vegetation fires have been observed at various heights in troposphere and occasionally even the lower stratosphere (Fromm et al., 2005). Smoke remnants from certain tropical fires have been observed at $15 \mathrm{~km}$ altitude (Andreae et al., 2004), and plumes from individual Canadian stand-replacing forest fires can also reportedly approach such heights (Damoah et al., 2006). For the largest events, observations from Fromm et al. (2010) show that a single fire was able to induce a significant average surface temperature decrease at the hemispherical scale. The emissions from such large fire events are capable of spreading extremely rapidly, and Dirksen et al. (2009) show that the transport of emissions from an Australian fire in 2006 spread around the globe in only 12 days.

Using EO data from the Multi-angle Imaging SpectroRadiometer (MISR) instrument onboard the Terra satellite (Kahn et al., 2008) we estimate that 5 to $18 \%$ of 664 plumes observed from boreal forest fires over Alaska and the Canadian Yukon in 2004 reached the free troposphere (FT). Using AI peak observation from TOMS, backward trajectories to identify location of the causal fire, and then GOES and/or American and Canadian fire report data bases for confirmation, Fromm et al. (2010) identify a total of 17 plumes that reached an altitude of at least $10 \mathrm{~km}$ for the year 2002. Fires whose smoke columns reach these elevations are also likely to be those that emit large quantity of gases and aerosols; therefore, even though such large and intensely burning fires are relatively less common than smaller, less intense events, their impacts are likely to be much greater than the "average fire" (Chen et al., 2009). Other evidence shows that fires from agricultural or grassland vegetation type (usually less intense than those from boreal forest) can also generate plumes reaching the FT. Amiridis et al. (2010) show that half of the agricultural fires they observed over eastern Europe for the period 2006-2008 reach heights above the PBL. Mims et al. (2010) show that $26 \%$ of the 27 Australian grassland 

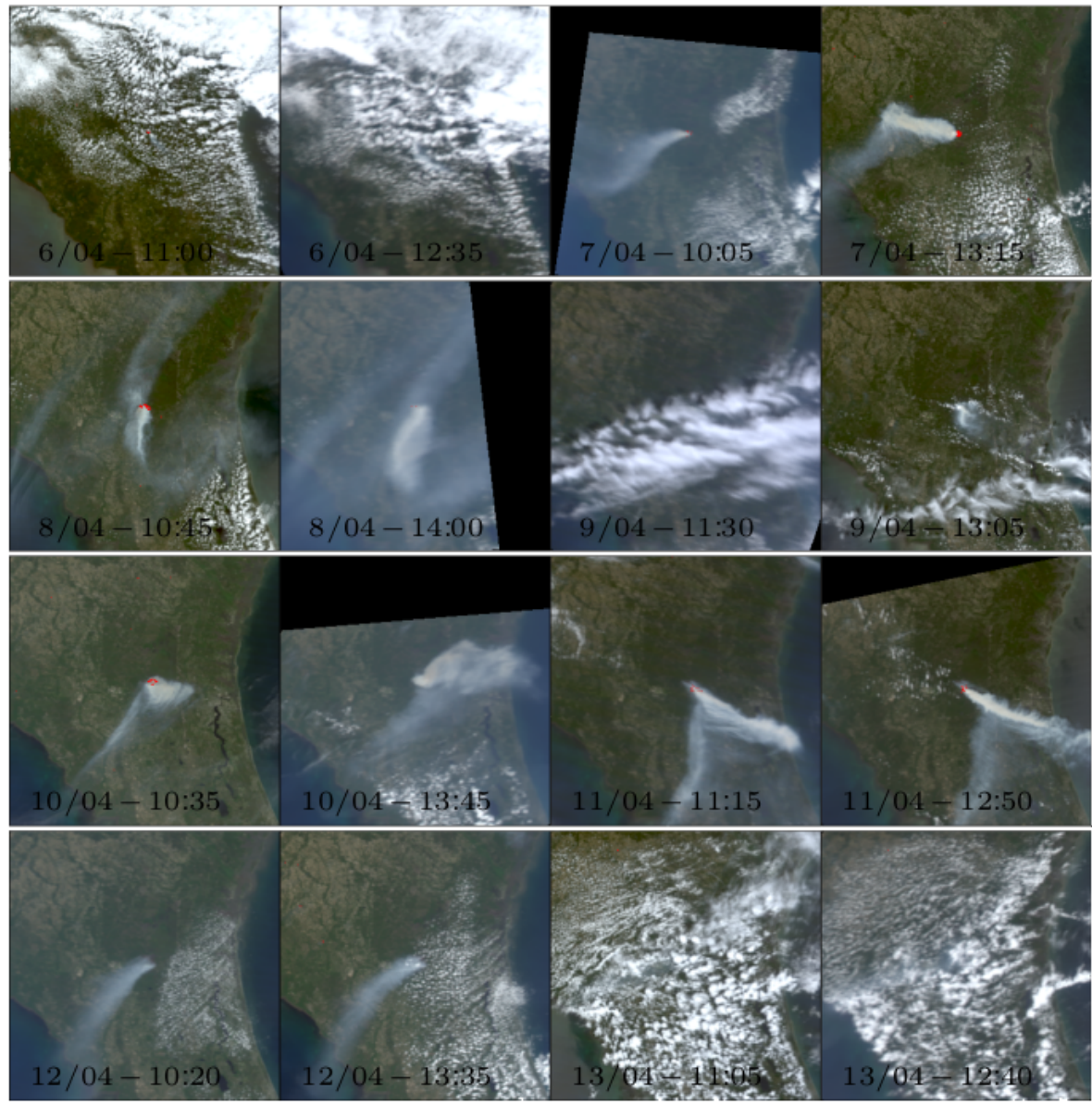

Figure 1. True colour composite of daytime observations of the county fire (USA), made from the Moderate Resolution Imaging Spectroradiometer (MODIS) satellite EO sensor. The fire occurred in Ocala National Forest (Florida) between 5 and 13 April 2012. MODIS data from all available Terra and Aqua satellite overpasses are shown, with the local time indicated. Overlain on the colour composite imagery are red vectors that outline pixels detected as containing active fires by the MODIS MOD14/MYD14 Active Fire and Thermal Anomaly Products (Giglio et al., 2003). The regularly changing nature of the fire and the smoke transport apparent from this time series, as well as the presence on some days of bifurcated plumes, is very apparent.

fires they studied with various stereo-height retrieval algorithms rose above the PBL. In summary, the height to which biomass burning plumes rise, and the distance over which the emissions are therefore transported, is highly variable. Possibly even more variable than fire behaviour, since the same fire burning under different ambient atmospheric conditions will probably result in different plume behaviours. It is important to note however that certain atmospheric conditions are more favourable to fire occurrence than others, such as high pressure (Kahn et al., 2007) and/or low moisture (dry season) conditions (Labonne et al., 2007).

Fully modelling the impacts of biomass burning emissions at large scales requires an understanding of plume dynamics, including their InjH. Some InjH inventories are already available, for example derived from satellite EO data of aerosols or CO. For example,
- Guan et al. (2010) screened aerosol index (AI) measurements extracted from data collected by the Ozone Monitoring Instrument (OMI) and the Total Ozone Mapping Spectrometer (TOMS) to map high aerosol clouds (> $5 \mathrm{~km}$ ) related to wildfires over the period 1978-2009;

- and Gonzi and Palmer (2010) use an inverse modelling method based on the GEOS-Chem model and EO-derived vertical measurements of $\mathrm{CO}$ concentration in the free troposphere and lower stratosphere (from the Tropospheric Emission Spectrometer (TES) and the Microwave Limb Sounder (MLS) sensors). The approach was able to retrieve an estimate of both the emitted $\mathrm{CO}$ magnitude and the injection height profile.

Although the above EO-based approaches are useful to understand and quantify the occurrence of wildfire plumes at different heights, they have limited sensitivity to the poten- 


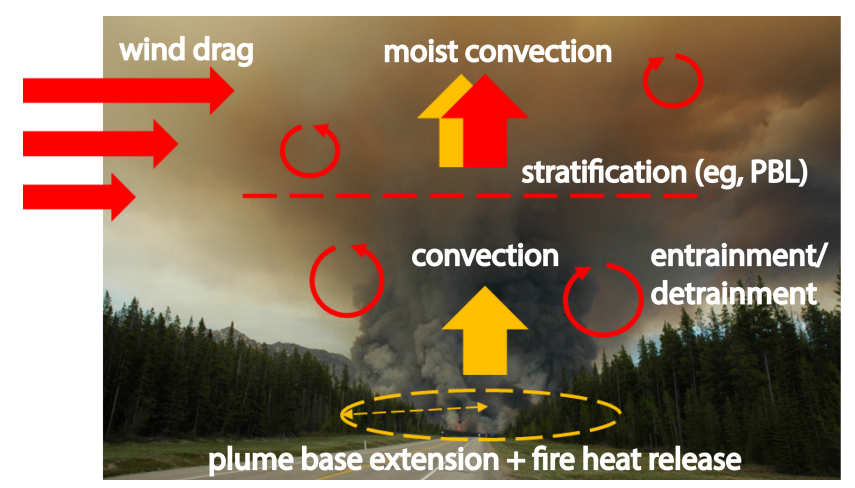

Figure 2. Schematic view of the physical processes involved in fire plume dynamics. Red and yellow colours stand for atmospheric or fire-induced mechanisms respectively.

tial variability of InjH. Both inventories are therefore quite difficult to couple to fire emissions inventories and cannot be easily linked to particular fires and therefore to actual emission totals. Capturing the high variability of plume dynamics, estimating $\mathrm{InjH}$, and implementing this within a CTM therefore remains a current topic of very active research (Freitas et al., 2010; Sofiev et al., 2012; Val Martin et al., 2012; Peterson et al., 2014), and the task of this paper is to review the different approaches currently available.

\section{Physics of landscape fire plumes}

The injection height of a smoke plume is controlled by the plume dynamics, which are driven by both the energy released by the fire and the ambient atmospheric conditions (both stability and humidity) (Kahn et al., 2007; Labonne et al., 2007). In the time period between the emissions being first released by the combustion process (which happens at the flame scale of $\sim \mathrm{mm}$ ), and their later release into the wider atmosphere (which operates on a metre to kilometre scale), the smoke emissions are trapped in the plume (see Fig. 2). Here the dynamics are dominated by

i. the buoyancy flux induced by the convective heat flux (CHF) generated by the fire itself;

ii. the size of the combustion zone, which controls the surface area of the plume interacting with the atmosphere (Freitas et al., 2007);

iii. the ambient atmospheric stratification which acts on the buoyancy of the initial updraft (Kahn et al., 2008) and also on the later level of the detrained smoke as smoke injected above the PBL tends to accumulate in layers of relative stability (Kahn et al., 2007; Val Martin et al., 2010; Mims et al., 2010);

iv. the degree of turbulent mixing occurring at the edge of the plume, which affects the entrainment and detrain- ment of ambient air into the plume and which slows down the initial updraft and control the release of the smoke into the wider atmosphere (Kahn et al., 2007);

v. the wind shear, which also affects horizontal mixing and therefore the ent-/detrainment mechanism in the plume;

vi. the latent heat released from the condensation of water vapour entrained into the plume from the combustion zone (water is a primary combustion product) and/or from the ambient fresh air (Freitas et al., 2007; Peterson et al., 2015).

In some scenarios, the combination of these processes initially triggered by the heat released from the vegetation combustion is capable to producing deep convection in places where natural convection would not normally be possible; the so-called pyroconvection phenomena (Fromm et al., 2010). Trentmann et al. (2006) show that in the case of large events like the Chisholm fire (documented by Fromm and Servranckx, 2003), the energy budget of the plume is essentially driven by the latent heat released from the condensation of the entrained water vapour.

Depending on the quantity of water vapour condensed during the plumes development, three types of vegetation fire plume can be identified (Fromm et al., 2010).

i. Dry smoke plumes containing water vapour rather than liquid droplets. These are typically created by smaller, weakly burning and low intensity fires and usually stay trapped in the PBL.

ii. Pyrocumulus (PyroCu), which are formed from cloud droplets. Water vapour here condenses in the plume after it has reached the altitude of the lifted condensation level (LCL). Depending of the stratification and ambient humidity of the atmosphere, these plumes may be trapped in the PBL or reach the FT.

iii. Pyrocumulonimbus (PyroCb) which contain ice particles present in an anvil shape capped over the plume. Such plumes can reach the stratosphere, aided by the extra heat released from the ice formation. They are not frequent but rather extreme scenarios that can be compared in nature to plumes from explosive volcanic eruptions. For example, Fromm et al. (2010) reported 17 events in North America for the year 2002, while for the same time period 73457 fires were reported only for the USA (source: National Interagency Fire Center). $\mathrm{PyroCb}$ are usually triggered by very large, intensely burning fires occurring in favourable atmospheric conditions for the phenomena. The exact conditions are still a matter of debate; however several studies have demonstrated the influence of fire size (Toon et al., 2007), unstable lower atmosphere (Kahn et al., 2007), the ambient mid-level moisture (Peterson et al., 2015), and/or the presence of an approaching cold front (Fromm et al., 
2010; Dirksen et al., 2009; Luderer et al., 2006; Peterson et al., 2015). For examples of PyroCb see the website http://pyrocb.ssec.wisc.edu, which has been reporting PyroCb events since May 2013.

Since the initial trigger of plume rise is the heat released by the casual fire, InjH are strongly influenced by fire diurnal cycles (Roberts et al., 2009). This leads to lower nocturnal $\mathrm{InjH}$ which are amplified by the combination of nighttime stable atmosphere and lower PBL (Sofiev et al., 2013). However some meteorological conditions can intensify fire activity over night, as for example the Santa Ana foehn wind (Sharples, 2009), and keep them running. Few observations of nocturnal plumes triggered by those intense fires are available (Fromm et al., 2010), and to our knowledge only Sofiev et al. (2013) tackle the issue of modelling nocturnal InjH. Their approach relies on a simulated diurnal cycle based on the high temporal resolution $(\sim 15 \mathrm{~min})$ fire radiative power (FRP) product of the geostationary orbiting satellite SEVIRI (Roberts and Wooster, 2008) and the parameterization of Sofiev et al. (2012) (further discussed in Sect. 5.2.1). Despite the low resolution of SEVIRI $(>3 \mathrm{~km})$, their empirical diurnal cycle captures the expected fire intensity increase at night, but no effects were found on InjH. Their resulting modelled InjH shows a strong diurnal pattern with low nocturnal InjH (e.g. maximum monthly mean nocturnal InjH lower than $2.5 \mathrm{~km})$.

Of course, a full understanding of the complex coupled mechanisms inherent in fire plume dynamics is extremely challenging, and many points remain unclear: for example, the role of soot and aerosol in the heat transfer within the plume column (Trentmann et al., 2006) and the effect of the number of initial cloud condensation nuclei on the triggering of pyroconvection (Reutter et al., 2013).

\section{Earth observation data used to support wildfire injection height estimation}

Sensors and imagers onboard EO satellites can provide various information on wildfire plumes, including their trace gas ratios (e.g. Coheur et al., 2009; Ross et al., 2013), aerosol burden (e.g. Kaskaoutis et al., 2011; Ichoku and Ellison, 2014), and their height, including on occasion the vertical distribution of material within them (e.g. Kahn et al., 2008). Ichoku et al. (2012) provide a recent review of this topic. EO data also provide information on the characteristics of the causal fires themselves, including "active fire" (AF) products that detail the location, timing, and FRP of the landscapescale fires occurring within the EO satellite pixels (Giglio et al., 2003; Giglio and Schroeder, 2014; Peterson et al., 2014; Wooster et al., 2012a; Roberts and Wooster, 2008). FRP is a fire characteristic that has been shown to relate quite directly to the total heat produced by the combustion process (Freeborn et al., 2008) and also to the rate of fuel consumption (Wooster et al., 2005), trace gas (Freeborn et al., 2008),

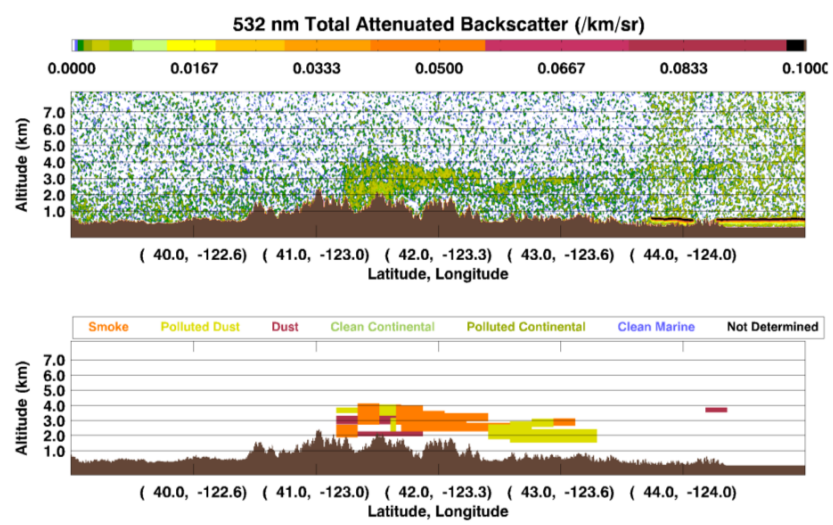

Figure 3. Example of profiles for Level-1 CALIOP $532 \mathrm{~nm}$ total attenuated backscatter data product (top) and the matching Level2 product of aerosol layers (bottom) for the 28 August 2006 over the Klamath Mountains in California and Oregon. The presence of aerosols classified as biomass burning smoke can be seen. Image from Raffuse et al. (2012).

and aerosol (e.g. Ichoku et al., 2012) emission. Such active fire products are usually derived from thermal wavelength Earth observations (Giglio et al., 2003; Roberts and Wooster, 2008; Wooster et al., 2012a).

No satellite product is yet able to derive information on plume heights at a spatial and temporal resolution than matches those of sensors used for active fire detection and smoke emission estimation, such as e.g. the Moderate Resolution Imaging Spectroradiometer (MODIS), Meteosat SEVIRI, or the Geostationary Orbiting Environmental Satellite (GOES) (Giglio et al., 2003; Roberts and Wooster, 2008; $\mathrm{Xu}$ et al., 2010). Therefore, determination of the injection heights at spatiotemporal scales and levels of completeness approximately matching these type of active fire observations is more likely to rely on InjH parameterizations.

\subsection{Direct measures of smoke plume height}

Smoke plume height can be evaluated from spaceborne platform using either Lidar technology (Sect. 4.1.1) or stereo-matching algorithm based on passing imaging system (Sect. 4.1.2).

\subsubsection{Spaceborne lidar}

The primary spaceborne lidar used for estimating smoke plume heights is the Cloud-Aerosol Lidar with Orthogonal Polarization (CALIOP), operated onboard the CALIPSO satellite. CALIOP provides a backscatter signal at 562 and $1064 \mathrm{~nm}$ over a $70 \mathrm{~m}$ wide ground track. Measures in the two wavebands are used to derive a Level-2 product that classifies aerosol layers into dust, smoke, or marine classes, as well as providing height profiles (see Fig. 3).

CALIPSO is part of the A-train satellite constellation and flies $75 \mathrm{~s}$ behind the Aqua satellite. The main advantage pro- 
vided by CALIOP is its high vertical resolution of $120 \mathrm{~m}$, and its main limitations are (i) noise effects created by sunlight that impact the results from daytime overpasses (Labonne et al., 2007) and (ii) the narrow ground track that limits the number of observed plumes that can be linked to their causal fires (Val Martin et al., 2010; Amiridis et al., 2010).

While the CALIOP Level-2 product is able to directly sense the altitude and thickness of the plume layer detrained in the atmosphere (see Fig. 3 for a particular case where the plume axis is capture by the CALIOP track), most studies only refer to the top plume height, which in most cases is used to determine the InjH measure (e.g. Val Martin et al., 2013).

Using CALIOP data, Labonne et al. (2007) examined plume heights from fires occurring in a number of countries and regions worldwide. Only in South Africa and Australia were definitive conclusions drawn, as in eastern Europe, Portugal, Indonesia, and the western United States cloud cover was too complete and/or CALIPSO overpasses were not well timed with regard to regions affected by fires. Whilst Labonne et al. (2007) did not examine collocated CALIOP and active fire product data, they did examine the bulk effect of fire emissions in South Africa and parts of Australia, where fire activity is mostly controlled by smaller, highly numerous savannah fires. They found that for most of the CALIOP ground track, the aerosol layer was trapped within the PBL. Their conclusion that most fires inject material into the PBL may be true for this type of fire activity but may not be the case for other regions such as forests where more intense fires can occur (Keeley, 2009). In another study based on CALIOP data covering eastern Europe, Amiridis et al. (2010) focused on agricultural fire emissions over 20062008. They found that $50 \%$ of the 163 fires examined were above the PBL, with injection heights ranging from 1677 to $5940 \mathrm{~m}$. Amiridis et al. (2010) collocated the CALIOP overpasses with MODIS active fire data from the Aqua satellite and used FRP measures derived from the MODIS observations as a proxy for the strength of the fire activity. They concluded that the aerosols seen to be located above the PBL were a direct result of fire emissions and were not related to large-scale atmospheric transport. Furthermore, they demonstrated that in the presence of an unstable atmospheric layer in the troposphere, a linear relationship holds between FRP (from MODIS) and plume-top height (from CALIOP). This is a similar result as that shown by Val Martin et al. (2010) with respect to MISR-derived plume heights (see below).

\subsubsection{Stereo-imagers}

Cloud-top heights have long been derived from stereo imaging, and the same methodology can be used to derive heights of smoke plumes (Mazzoni et al., 2007). The primary instrument used for this purpose is the MISR, operated aboard the NASA Terra satellite. This satellite is not part of the A-train
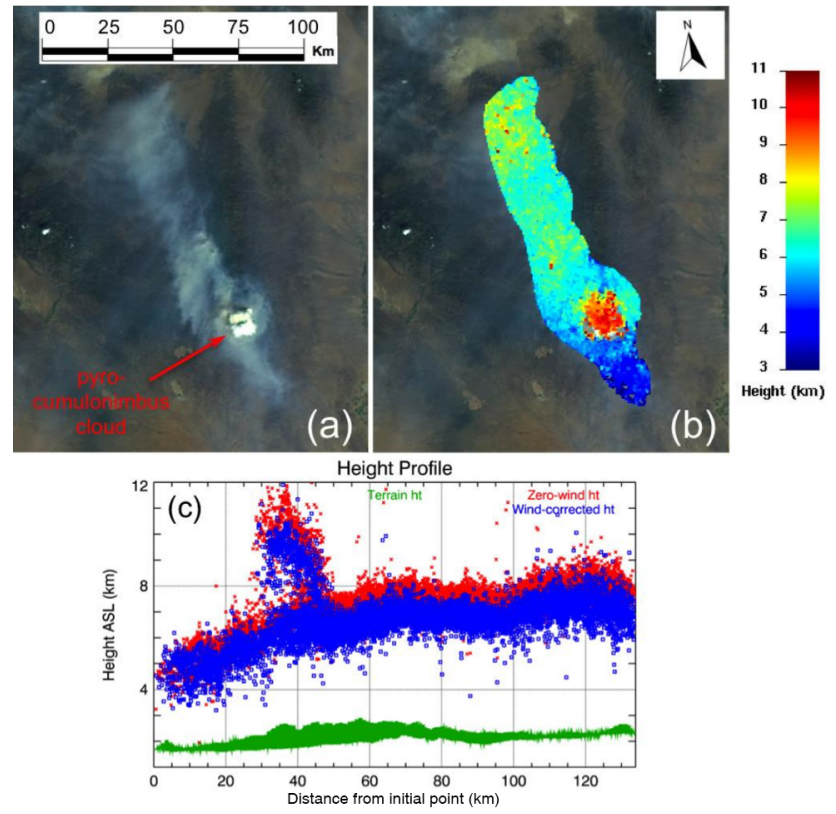

Figure 4. Example of smoke plume height derivation using data from the Multiangle Imaging SpectroRadiometer (MISR) that operates on the Terra satellite. This example is extracted from Nelson et al. (2013). The fire took place on the 12 July 2013 in New Mexico and was observed by MISR at 18:09 UTC. The MISR nadir RGB image showing a smoke plume in grey and a PyroCb in bright white is reported in (a), when the plume stereo-heights derived from the MINX software (Nelson et al., 2013) are shown in (b). MINX height retrieval profiles are shown in (c). Note the dramatic difference in the heights which reach 11-12 km a.s.l. in the PyroCb and stay trapped in a layer around $6-8 \mathrm{~km}$ a.s.l. in the vicinity.

but rather has a daytime Equator crossing of around $3 \mathrm{~h}$ before Aqua (at 10:30 a.m.).

MISR can retrieve (i) total column aerosol optical thickness and (ii) the altitude of the atmospheric cloud or aerosol layer over cloud-free land and water surfaces. The altitude retrieval is based on a stereo-matching algorithm that uses the nine MISR collocated images available for each location wherever clouds or aerosol plumes have discernible spatial contrast, with about $500 \mathrm{~m}$ vertical accuracy at a $1.1 \mathrm{~km}$ horizontal resolution (Kahn et al., 2007). The $380 \mathrm{~km}$ swath of MISR is centred within the $2330 \mathrm{~km}$ swath of the MODIS sensor present on the Terra satellite. Up to now, the specific derivation of smoke plume height from raw MISR data has been made using the MINX software tool (Nelson et al., 2013). Figure 4 shows an example of MINX output for a wildfire smoke plume, and Val Martin et al. (2010) provide full details of the use of MINX for this purpose. One constraint of MINX is the manual nature of the process required to digitize the smoke plume contour, used by the algorithm to compute the wind vector during the plume height retrieval. This wind vector is required to correct for the displacement occurring between the times of the nine collocated but differ- 
ently angled MISR views. Post-processed plume heights for more than 25000 plumes worldwide are accessible through the MISR Plume Height Project ${ }^{1}$.

Because of its relatively high degree of spatial coverage Kahn et al. (2008) estimate that MISR is at a minimum 40 times more likely to observe a plume that can be linked to a causal fire than CALIOP is. Kahn et al. (2008) explain that MISR and CALIOP are, however, highly complementary since (i) they have different overpass local time as they are on differently orbiting satellites and (ii) CALIOP is able to detect optically thin older plumes, while MISR is essentially sensitive to only young plumes exhibiting high contrast with the background. One major drawback of MISR is, however, its relatively early daytime overpass, which limits its ability to observe mature PyroCu as they typically reach their maturity in the late afternoon (around 18:00 local time; Fromm et al., 2010). Therefore, MISR-derived plume heights are biased toward lower altitude plumes (Val Martin et al., 2010). The relative lack of highly elevated plume observations from MISR was also reported by Chen et al. (2009). For some of the fire events encountered in their study, Chen et al. (2009) pointed out that the subsequent transport of $\mathrm{CO}$ and black carbon were better captured by a crude model of homogeneously spread emissions up to the top of the troposphere than by an emission profile based on MISR-derived plume heights.

Statistical analyses of MISR-derived plume height data are available in Kahn et al. (2007), Mazzoni et al. (2007), Kahn et al. (2008), Val Martin et al. (2010), Tosca et al. (2011), and Jian and Fu (2014). These studies confirm that the majority of the detected plumes are trapped within the PBL, though geographical location and land cover type have an influence. For example, Kahn et al. (2008) show in their study on fires located in Alaska and the Yukon regions that 5 to $18 \%$ of the fires they observed for the summer 2004 reach the free troposphere, while Tosca et al. (2011) showed that the quasitotality of fires observed in Borneo and Sumatra (areas impacted strongly by peat fires) from 2001 to 2009 (317 fires) were trapped in the PBL. Val Martin et al. (2010) conducted a detailed analysis of the MISR-derived plume height data for fires in North America over a 5-year time period (2002, 2004-2007), finding no clear rules governing the capability of plumes to reach the FT, even when the fires were split per biome. However, Val Martin et al. (2010) show that the percentage of plumes reaching the FT in forest fires (more intense) was larger than crop/grassland fires (less intense).

The along-track scanning radiometer series of sensors have provided a $512 \mathrm{~km}$ wide swath stereo-viewing capability since 1991 (Prata et al., 1990), and recently Fisher et al. (2014) developed an automated stereo-height retrieval algorithm (M6) working with data from the advanced along-track scanning radiometer (AATSR). Unlike MINX, M6 is not able

\footnotetext{
${ }^{1}$ http://www-misr.jpl.nasa.gov/getData/accessData/ MisrMinxPlumes/
}

to correct for the plume displacement induced by the ambient wind. However, it was estimated that such correction would lie in the error of the M6 algorithm (D. Fisher, personal communication, 2015). M6 was applied to AATSR data of Eurasian boreal forests for the April-September period of 4 years between 2008 and 2011 and showed successful comparisons with collocated observations of smoke layer height derived from CALIOP lidar collections and MINX-derived stereo-heights from MISR. Unfortunately, AATSR also has a bias towards low injection heights since the overpass time is similar to MISR. A wider swath instrument following on from AATSR, the Sea and Land Surface Temperature Radiometer (SLSTR), will operate from 2015 (Wooster et al., 2012a). However, this will still not provide daily stereo-data worldwide, and with a limited number of stereo-observations the continuous, direct measurement of smoke plume heights at the global scale appears to be a difficult task.

\subsection{Measure of buoyancy flux and fire size}

Among the processes inherent to the plume dynamics and listed in Sect. 3, the buoyancy flux and the fire size are the two sets of information needed to characterize the fire. The buoyancy flux generated by the combustion heat release is the primary source of energy responsible of the plume rise. The latent heat, which provides energy to the plume is a secondary source, can only be trigger if the plume reaches its LCL altitude. This LCL altitude can be different from the atmospheric LCL as water content and temperature profiles in plume usually differ from the ambient conditions. To understand the behaviour of the plume dynamics and explain variation in InjH, quantitative information on both the buoyant flux and the fire size is therefore needed. The vertical buoyant flux $F$ is defined as (Viegas, 1998)

$F=g \frac{\left(\rho-\rho_{0}\right)}{\rho} w=\frac{g R}{c_{p} p_{o}} Q_{\mathrm{c}}$,

where $g$ is the gravity constant, $R$ is the ideal gas constant, $\rho$ is the density of the plume, $w$ is the vertical velocity of the plume, $\rho_{o}$ and $p_{o}$ are the ambient density and pressure, $c_{p}$ is the heat capacity at constant pressure, and $Q_{\mathrm{c}}$ is the convective heat flux. In large-scale models $(>100 \mathrm{~m})$ wildfires are usually represented with a constant partition of convective and radiative energy emission (Trentmann et al., 2006; Freitas et al., 2007) with a ratio $\beta$ of convection to radiation ranging from 1 to 5 , so that $Q_{\mathrm{c}}$ is related to the radiative heat flux $Q_{\mathrm{r}}: Q_{\mathrm{c}}=\beta Q_{\mathrm{r}}$. The values of $\beta$ are essentially based on experimental studies performed at small scale (Freeborn et al., 2008; McCarter and Broido, 1965), and their applications to large scale remain uncertain. In a model sensitivity study of the Chisholm fire run with the high-resolution threedimensional plume model ATHAM, Luderer et al. (2006) show that a ratio $\beta$ greater than unity is crucial in their case to trigger the mechanism of pyroconvection. With value of $\beta$ 
lower than unity, not enough latent heat is able to reach the condensation level.

A bi-spectral algorithm based on middle infrared (MIR) and thermal infrared bands was proposed by Dozier (1981) to estimate the kinetic temperature $T_{\mathrm{f}}$ and the AF area $A_{\mathrm{f}}$ of the black body that would emit the same radiances as the observed fire. According to the Stefan-Boltzmann equation, $Q_{\mathrm{r}}=\sigma T_{\mathrm{f}}^{4}$, where $\sigma$ is the Boltzmann constant. This makes the buoyancy flux $F$ a direct function of $T_{\mathrm{f}}$. The Dozier algorithm is therefore able to provide all information necessary to characterize the fire (i.e. $F=f\left(T_{\mathrm{f}}\right)$ and fire size) as AF area can be used as a proxy for the fire size.

Several implementations of this algorithm have been developed and used with sensor of different resolution: e.g. the BIRD Hot spot Recognition Sensor (185 m, Zhukov et al., 2006), MODIS (1 km, Peterson et al., 2013), or GOES (3 km, Prins et al., 1998). The algorithm is found to be highly sensitive to the determination of the long-wave brightness temperature background (Giglio and Kendall, 2001) and to a lesser extent to the atmospheric transmittance (Peterson and Wang, 2013). As a result it is not converging for $\approx 10 \%$ of the case. However, this method represents the best available option to estimate buoyancy flux and fire size.

\section{Current representation of wildfire emissions injection height in CTMs}

A number of studies have determined the very serious implications that incorrect InjH estimates have on the ability of CTMs to represent emissions transport (e.g. Hodzic et al., 2007; Turquety et al., 2007). Consequently it may also effect (i) "top-down" emission estimates based on the inversion of observed atmospheric concentrations of biomass burning species (Ichoku and Ellison, 2014) and (ii) radiative forcing studies (Ward et al., 2012). This section aims to review the different parameterizations that are currently available to tackle the issue of InjH. They are based either on empirical, deterministic, or statistical models.

\subsection{Simple approaches: empirical and/or best-guessed profiles}

Because of the complexity of fire plume dynamics, in the early endeavour of biomass burning impact on the atmosphere, CTMs often assume a single fixed altitude for all biomass burning emissions usually presuming that all pollutants are contained solely within the PBL (e.g. Pfister et al., 2008; Hyer and Chew, 2010). However, such assumption cannot represent the observed variability of injection height described in Sect. 2. To improve the representation of fire emission at large scale, some studies used a prescribed fixed profile either build on (i) simple hypothetical ratio between boundary layer and tropospheric emission (e.g. Turquety et al., 2007; Leung et al., 2007; Elguindi et al., 2010) or (ii) average local observations (Chen et al., 2009). In the latter work, the authors use the GEOS-Chem model with different vertical and temporal emissions distribution to simulate $\mathrm{CO}$ and aerosol transport over North America during the fire season 2004. Comparing their simulation results with satellite-, aircraft-, and ground-based measurements, they show that the use of finer temporal distribution enhances long-term transport, while changes due to different $\mathrm{InjH}$ implementation are small. However, as already mentioned in Sect. 4.1, they also point out that the finer vertical modelled profile emission they implemented is probably affected by MISR observation bias. Most of these early studies do not provide grounded solutions to the problem of fire emission injection role in the atmospheric circulation but rather emphasize the challenge of developing InjH models.

\subsection{Deterministic models}

\subsubsection{InjH models description}

Several studies develop deterministic models capable of being host in CTMs. They are usually based either on physical or dimensional analysis. Goodrick et al. (2013) review the different type of existing plume rise models. In particular, they discuss the use of plume rise models in the framework of the Blue Sky project, which aims to derive smoke emission for air quality models such as the Community Multiscale Air Quality (CMAQ) modelling system. Here, we limit our review to plume rise models originally built to handle fire plume dynamics (see list of physical processes in Sect. 3). Models like Daysmoke (Achtemeier et al., 2011) or the Briggs equation (Briggs, 1975), which are both available in the CMAQ system, are more suitable for small fires like control burns (Achtemeier et al., 2011) to forecast or prevent emission dispersion and air pollution (i.e. local $\mathrm{PM}_{2.5}$ concentration). When used with wildfires, they generally fail to predict large fire impact, certainly because of their weak representation of microphysical processes (Achtemeier et al., 2011) which affect the simulation of PyroCu and PyroCb plumes. For example, using the Briggs equation and the CMAQ model to simulate fires emission in the USA between 2006 and 2008, Raffuse et al. (2012) show that most of their plumes where below the level expected from remote-sensing measurement.

At present, three parameterizations of plume rise model stand out of the literature, namely Freitas et al. (2007), Rio et al. (2010), and Sofiev et al. (2012). A brief description of each models is reported below.

- Freitas et al. (2007, 2010) develop a one-dimensional cloud-resolving model (hereafter named Plume Rise Model version 0, PRMv0) based on the original plume model of Latham (1994), in which equations for vertical momentum, first thermodynamic law, and continuity of water phases are solved explicitly. The model is solved offline and the final injection height is then used 
in the host CTM. In their approach the fire is modelled as an homogeneous circle defined with (i) a size derived from the active fire area of the WF-ABBA GOES product (Wild Fire Automated Biomass Burning Algorithm; Prins et al., 1998) (ii) and a buoyant flux/CHF calculated as a constant fraction of the total heat. The total heat is set as a prescribed value depending of the vegetation type. The cloud physics is based on a simple microphysical module counting three hydrometeors (cloud, rain, ice). Additionally, the horizontal momentum is parameterized through two entrainment coefficients modelling the effect of (i) the turbulence at the edge of the stack $\left(\propto \frac{|w|}{R}\right.$; Freitas et al., 2007) and (ii) the drag caused by the ambient wind shear $\left(\propto \frac{\left(u_{e}-u\right)}{R}\right.$; Freitas et al., 2010). In previous formula, $R$ is the radius of the plume, and $u$, $u_{e}$, and $w$ are the horizontal plume, horizontal ambient, and vertical plume velocities respectively. $R, u$, and $w$ are prognostic variables of the model.

- Rio et al. (2010) implement in the LMDZ model a parameterization based on an eddy diffusivity/mass flux (EDMF) scheme originally developed to model similarly shallow convection and dry convection. In comparison with the implementation of Freitas et al. (2007), this adaptation of EDMF for pyroconvection (pyroEDMF hereafter) is not based on prognostic equation solved offline but rather evaluates turbulent fluxes produced by the temperature anomaly created by the fire at a sub-grid level and directly adds the source term to the transport equations of the conservative variables of the host CTM. The fire is considered a sub-grid effect and its $\mathrm{CHF}$ is modelled as a fraction of the surface sensible heat flux averaged over the host model grid cell. The interest of this approach is that the dynamics of the plume is coupled with the ambient atmosphere, so that for example change in the stability of the atmosphere induced by the fire can impact the later development of the plume. In their approach, Rio et al. (2010) apply this extra turbulent flux to the total water, the liquid potential temperature, and the $\mathrm{CO}_{2}$ concentration, so that the effect of latent heat can be handle in the CTM, simplifying the formulation of the parameterization. The mass flux formulation of pyro-EDMF relies on the definition of two entrainment and detrainment fluxes which are set differently in the PBL and above. Therefore, the mass transfer between the plume and the ambient atmosphere is solved all along the plume. One limitation of the current version of pyro-EDMF is that ambient shear at subgrid level is not represented. This certainly overpredicts injection height of small fires which are more sensitive to wind drag.

- Sofiev et al. (2012) use energy balance in the up-draft and some dimensional analysis to develop an equation for the prediction of plume top height based on input of the FRP, the Brunt-Väisälä frequency, and the PBL height. The equation parameters are fitted using a learning data set of plume height measurement randomly selected in the MISR data set. This formulation does not take explicitly into account effects from either entrainment, cloud formation, or ambient wind shear. Another limitation of the equation of Sofiev et al. (2012) is inherent to the selection of the fires used to fit the equation parameters. All events from the learning (and the control) data set used in this study are lower than $4 \mathrm{~km}$. This implies that few PyroCu and certainly no PyroCb are present in the fit of the model.

\subsubsection{InjH model validation: fire per fire comparison}

Although validation on a fire per fire basis appears to be the best way to ensure the correct functioning of plume rise parameterization, because when implemented in the host model it is highly coupled with the large-scale circulation, few validation exist and generally show poor agreement. In their original presentation, PRM and pyro-EDMF have been compared with documented fire events as for example the threedimensional LES simulation of the Chisholm fire (Trentmann et al., 2006), but those tests (Freitas et al., 2010; Rio et al., 2010) are far from being a systematic validation ranging over different fire and atmosphere configuration. Example of those comparisons are reported in Figs. 5 and 6 for PRMv0 and pyro-EDMF respectively.

Sessions et al. (2010) propose the first evaluation of the PRMv0 model. They run a comparison against $\sim 600$ fires events captured by MISR that occur in Alaska in spring 2008 during the 10 days of the NASA Arctic Research of the Composition of the Troposphere from Aircraft and Satellites (ARCTAS) campaign. They implement two fire initialization schemes, both based on WF-ABBA and MODIS data for fire detection but using different temporal representation of the fire size based on either the diurnal cycle estimated in the FLAMBE inventory or kept constant as in the preprocessing of WRF-Chem. They found the best comparison PRMv0-MISR for the FLAMBE-based initialization with a one-to-one correlation of 0.45 . They infer the bad response of PRMv0 partly to the quality of their atmospheric profile, emphasize the importance of correct atmospheric profile as already mentioned by Kahn et al. (2007) or Kukkonen et al. (2014).

More recently, Val Martin et al. (2012) compare a subset of the MISR data set for North America with prediction from an improved version of PRMv0. Their model (PRMv1 hereafter) keeps the same model core but uses a new initialization module where $\mathrm{CHF}$ and fire size information are derived for each fire from MODIS observation. Despite a selection of several method to estimate PRMv1 input data, Val Martin et al. (2012) show that over the large range of conditions encountered, PRMv1 is not able to reproduce the plume heights observed by MISR or to even locate the fire correctly above 

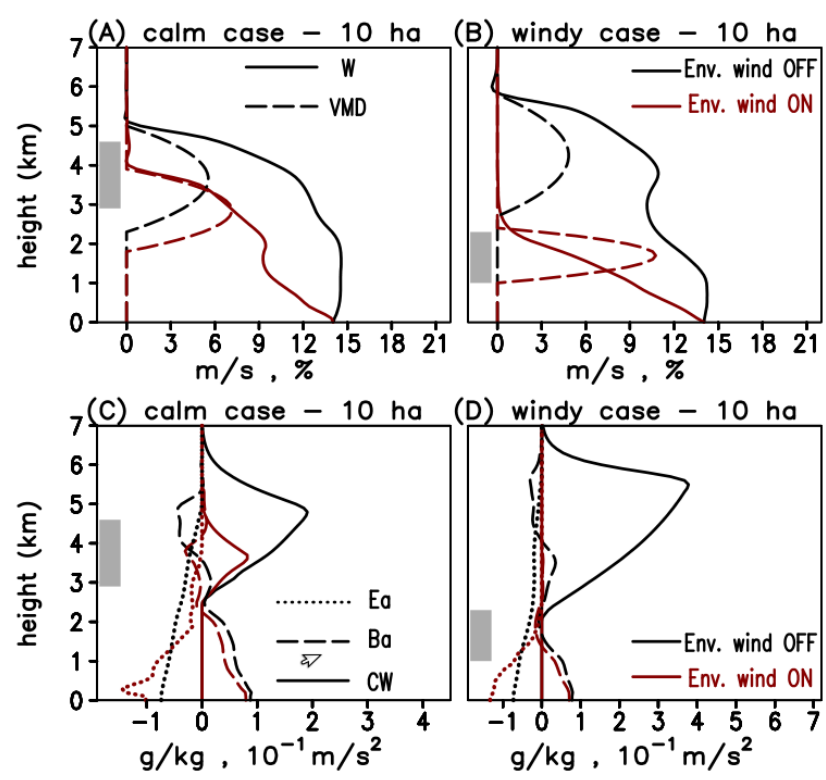

Figure 5. Results from the one-dimensional plume rise model (PRM) of Freitas et al. (2007, 2010) for a fire burning in (a, c) calm and $(\mathbf{b}, \mathbf{d})$ windy atmosphere scenario, as studied by Freitas et al. (2010). The fire has an active fire area (AF area) of 10 ha. The quantities shown are vertical velocity $\left(\mathrm{W}, \mathrm{ms}^{-1}\right)$, vertical mass distribution (VMD, \%), entrainment acceleration (Ea, $10^{-1} \mathrm{~ms}^{-2}$ ), buoyancy acceleration $\left(\mathrm{Ba}, 10^{-1} \mathrm{~m} \mathrm{~s}^{-2}\right)$, and total condensate water $\left(\mathrm{CW}, \mathrm{g} \mathrm{kg}^{-1}\right)$. Model results considering the environmental wind drag are shown in red, whilst those in black depicts the results from simulations disregarding this effect. Grey rectangles indicate the main injection height simulated by the three-dimensional ATHAM model (Trentmann et al., 2006) for the same fire scenario. Figure from Freitas et al. (2010).

or below the PBL. Their comparison is based on a total of 584 plumes selected from the MISR data where the following constraint apply: the plume height is computed immediately above the fire (not from the whole plume as in the original MISR data), the plume is formed of at least five stereo-height retrievals, the clustered MODIS fire pixels are located within $2 \mathrm{~km}$ of the plume origin, and the terrain height of the input atmospheric profile do not differ from the terrain elevation used in the MINX software by more than $250 \mathrm{~m}$. Despite this data quality screening, the best one-to-one correlation they obtain is about 0.3 .

In their approach, Sofiev et al. (2012) use the whole MISR data set (counting 2000 fires at that time) without any filtering. Because of its derivation based on an optimization procedure, their model compares relatively well to the selected MISR data. However, when compared with the current full data set for North America, results are not as good, showing a constant underestimation of plume height, in particular for high plumes. Figure 7 shows together a comparison of our implementation of the Sofiev model against (i) the original version of the model (ii) and against 3206 "good" quality flag fires of the North American subset of the MISR data set. Even if our implementation of the model exhibits a slight positive bias (certainly due to a different estimation of the PBL height which we read from the diagnostic products of the forecast run of ECMWF, 2012), our comparison with the MISR data shows a strong negative bias of the model. Similar behaviour was also shown for PRMv1 in the study of Val Martin et al. (2012). When compared with the PRMv1 sensitivity study of Val Martin et al. (2012) (Fig. 7b and Fig. 2 of Val Martin et al., 2012, show the same metrics), the Sofiev model does not perform better, showing a regression line slope of 0.4 for the Sofiev model against 0.8 for the best set-up of PRMv1. Note however that here we are using a larger extent of the MISR data set than in Val Martin et al. (2012).

\subsubsection{InjH models implementation}

Despite the lack of conclusive fire per fire validation (see previous section), plume rise parameterizations have been implemented in several regional and large-scale models. PRMv0 has been coupled with the Weather Research and Forecasting (WRF) Model (Sessions et al., 2010; Grell et al., 2011; Pfister et al., 2011) and the Coupled Aerosol and Tracer Transport model to the Brazilian developments on the Regional Atmospheric Modelling System (CATT-BRAMS; Freitas et al., 2009; Longo et al., 2010). Additionally, pyroEDMF is present in the mesoscale non-hydrostatic model (MesoNH; Strada et al., 2012) and the general circulation model LMDZ (Rio et al., 2010). See Table 1 of Val Martin et al. (2012) for a more complete list of atmospheric models with plume rise parameterization.

Several studies highlight the need to inject fire emission at high altitude (Turquety et al., 2007; Elguindi et al., 2010), and recent in situ (Cammas et al., 2009) and remote-sensing (Fromm et al., 2010) observations show the frequent occurrence of large PyroCb. However, the role of plume rise parameterization in transport of fire emission at a large scale in CTM simulation is still a matter of debate. A list of different conclusion from recent studies is reported below.

- Sessions et al. (2010) who are using PRMv0 embedded in WRF-Chem, simulate 10 days of the Spring 2008 ARCTAS campaign. As for their fire per fire comparison (see previous section), they show that among their two initialization schemes, the use of the FLAMBE-based initialization gives the best emission transport when compared with the Atmospheric InfraRed Sounder (AIRS) total columns CO and CALIOP aerosol profiles. Also a comparison with coarser injection schemes (distributing all fire emissions in the PBL or between altitude levels of 3 and $5 \mathrm{~km}$ ) shows that the use of PRMv0 is improving the simulation.

- Rio et al. (2010) run simulations of the LMDZ model over the month of July 2006 for Africa on a strip lo- 

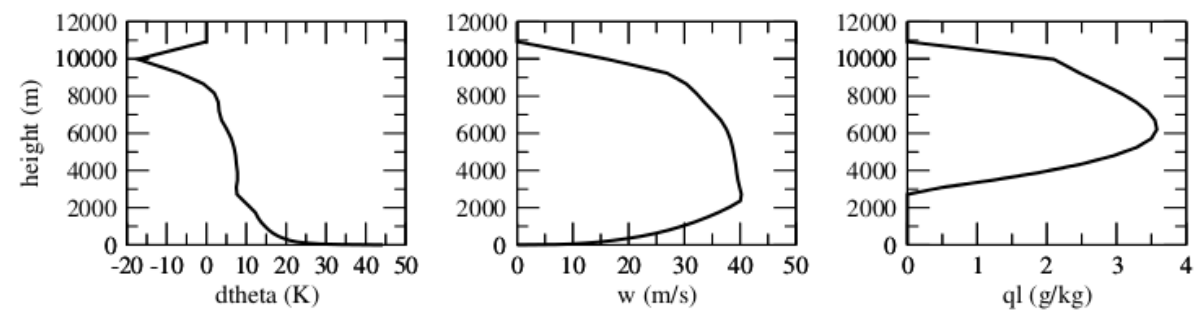

Figure 6. Smoke plume characteristics for the Chisholm fire, as simulated by pyro-EDMF: virtual potential temperature (K), vertical velocity excess $\left(\mathrm{m} \mathrm{s}^{-1}\right)$, and cloud liquid water $\left(\mathrm{g} \mathrm{kg}^{-1}\right)$ are shown. Figure from Rio et al. (2010).

(a)

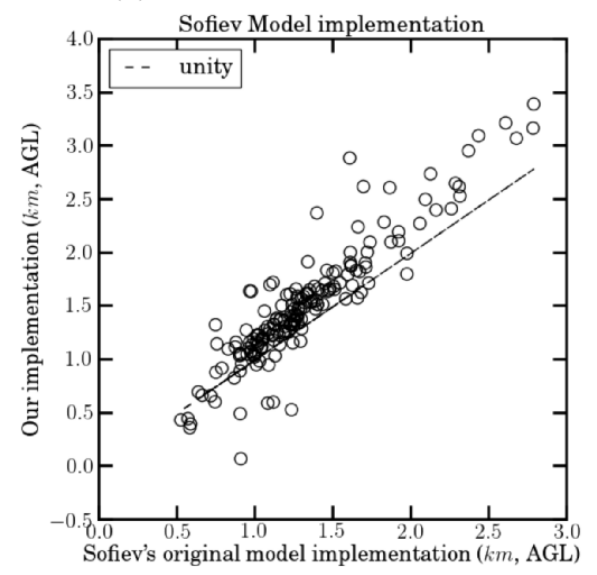

(b)

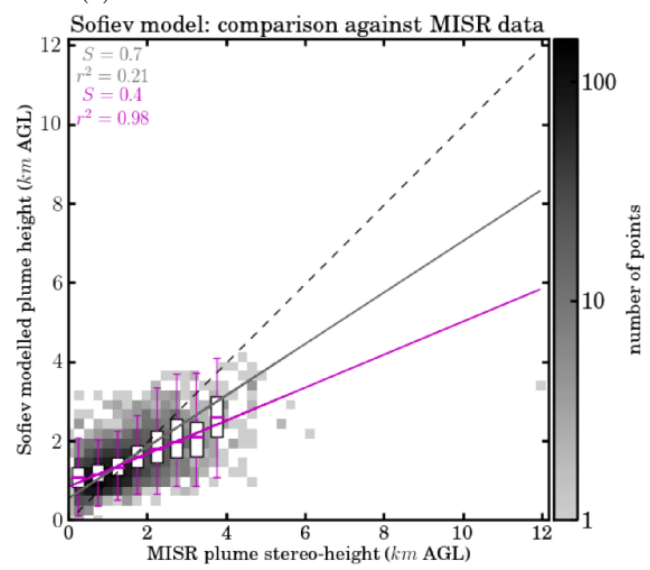

Figure 7. Comparison of our implementation of the plume rise parameterization of Sofiev et al. (2012) to (a) the original results from Sofiev et al. (2012) for the same fires and (b) plume stereo-height retrievals extracted from the North American subset of the (MISR) plume height project data Nelson et al. (2013), derived using the MINX tool as shown in Fig. 4. Our implementation of the Sofiev et al. (2012) model differs from the original in its definition of the PBL height, which in our approach is extracted from the diagnostic product of ECMWF forecast runs (ECMWF, 2012). See Figs. 9 and 10 for a statistical overview of the North American MISR data set. Note that the Sofiev et al. (2012) model did not retrieve simulated plume heights for all the 3320 selected fires of that data set. For 114 fires, either the Brunt-Väisälä frequency could not be retrieved or the FRP of the most powerful pixel listed in the MISR product was unavailable (see Sofiev et al., 2012, for details in the initialization of the model). Panel (b) shows the same metrics as Fig. 2 of Val Martin et al. (2012), i.e. two-sided regression line (grey), box plots of the distributions of model heights and $500 \mathrm{~m}$ resolution MISR heights for central $67 \%$ (box) and central $90 \%$ (cap), median distribution regression line (magenta), and $1: 1$ relationship (dashed black).

cated in the tropics between 5 and $20^{\circ}$ south. Fires locations and emissions are estimated from the burnt area product L3JRC while fire activity is idealized with a constant fire area of $2 \mathrm{~km}^{2}$ and a Gaussian diurnal cycle peaking at 15:45 LTC. Figure 8 show results from their simulations for different values of their parameter $\beta$ which defines the ratio between the entrainment $(\epsilon)$ and detrainment $(\delta)$ coefficients for the levels located above the PBL. Both $\epsilon$ and $\delta$ are set constant (no altitude dependence) and inversely proportional to the base of the plume radius. Their results show that pyro-EDMF is sensitive to the value of the parameter $\beta$ as the detrainment altitude control the final spread of the smoke emission. Rio et al. (2010) also show that LMDZ was able to predict the daily tropospheric emission (DTE) of $\mathrm{CO}_{2}$ (daily variation of $\mathrm{CO}_{2}$ in the troposphere) observed by Chédin et al. (2005). However, their simulated amplitude of DTE for southern Africa is much lower than the observed value. Rio et al. (2010) focus only on tropical fire in Africa. In the tropics, natural convection is more active than in higher latitude and firegenerated heat and vertical water transport could be a trigger to initiate natural convection (private communication Ben Johnson). Testing pyro-EDMF on a boreal forest fire scenario would be interesting.

- Grell et al. (2011) run the WRF model coupled with PRMv0 initialized with fire size input data estimated from in situ measurement. Running WRF at cloudresolving scale over Alaska for 2 days for summer 2004, they show that the use of PRMv0 improves the results when compared to radio sounding.

- Pfister et al. (2011) run WRF-Chem coupled with PRMv0 to examine CO budget in California over 1 
(a)

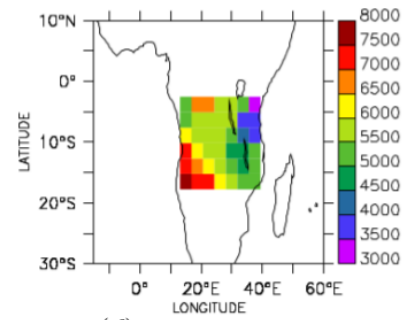

(d)

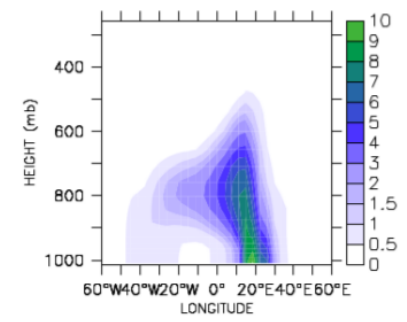

(b)

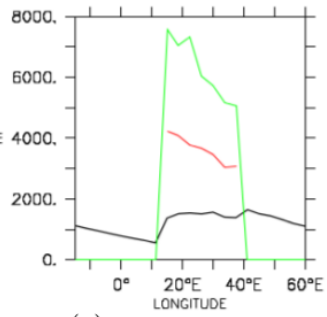

(e)

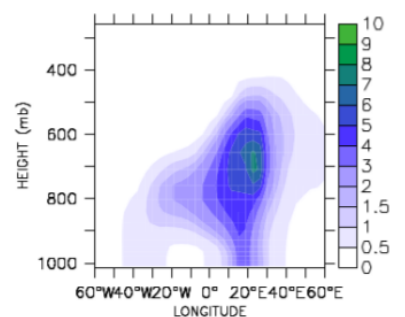

(c)

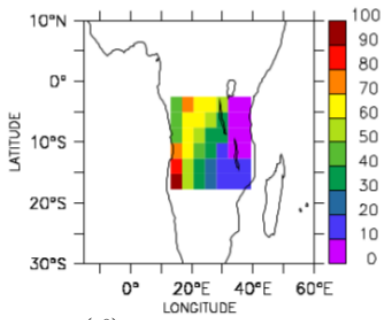

$(f)$

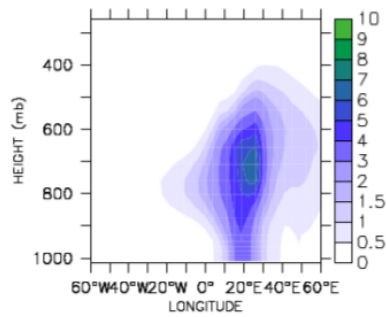

Figure 8. Simulations performed using the pyro-EDMF plume rise model of Rio et al. (2010) for sub-Saharan Africa between 10 and 30 July 2006. In the upper panel, (a) shows the maximal injection height of $\mathrm{CO}_{2}$ emissions simulated with the LMDZ model and pyro-EDMF between 5 and $20^{\circ} \mathrm{S}$ over the 20 days of the simulation. (b) reports the maximal injection height (green), mean injection height of emissions injected above the boundary layer height (red), and mean boundary layer height (black) averaged between 5 and $20^{\circ} \mathrm{S}$ altitude and over the 20 days of the simulation. (c) shows the percentage of cases for which the injection height passes the boundary layer height. In the lower panel, (e) shows the averaged vertical distribution of $\mathrm{CO}_{2}$ mixing ratio (ppmv) for the same reference simulation and (d) for simulations without pyro-EDMF and (f) with pyro-EDMF set up with a lower value of the ratio $\beta=\frac{\text { entrainment }}{\text { detrainment }}=0.1$ (right). The reference simulation in (e) uses a value of $\beta=0.4$. Figure from Rio et al. (2010).

month of the summer of 2008, coinciding with the ARCTAS campaign. WRF-Chem was also coupled with the global Model for OZone and Related Chemical Tracers (MOZART) which is used to provide boundary conditions. Such a system allows the estimation of the relative importance of local sources versus pollution inflow on the distribution of $\mathrm{CO}$ at the surface and in the free troposphere. Fire emissions are based on the FINN inventory (Wiedinmyer et al., 2011) which in their case study shows a clear underestimation of $\mathrm{CO}$ emission over California. Model results are compared against airborne and ground measurement of $\mathrm{CO}$ as well as $\mathrm{CO}$ total column from MOPITT. In the perspective of InjH modelling, Pfister et al. (2011) show that (i) in their case study PRMv0 injects half of the fire in the FT and captures the timing and location of fire plume well when compared to airborne $\mathrm{CO}$ measurements (ii) and that their comparison with surface measurement is impacted by a large underestimation of $\mathrm{CO}$ fire emission in the FINN inventory.

The conclusions of these studies emphasize the fact that the evaluation of plume rise effects on large-scale atmospheric transport simulation is a challenging task. As emission transport is dependent of both quantity and the geographical location of the injection, both emission inventory and local condition (i.e. atmospheric profile) need to be correctly input to allow the evaluation of $\mathrm{InjH}$ estimation.

\subsection{Statistical models}

As an alternative to the unreliable prediction of the PRM model, a statistically based approach using 584 plume height measurements of the MISR data set was presented by Val Martin et al. (2012). Classifying observed fires between low $(<1 \mathrm{~km})$, medium $(<2.5 \mathrm{~km})$, and high $(>2.5 \mathrm{~km})$ plumes, they derive per biome the mean and standard deviation of FRP (MW) and atmospheric stable layer strength $\left(\mathrm{K} \mathrm{km}^{-1}\right.$ ) for each plume height class (See Table 4 of Val Martin et al., 2012). Although this approach is attractive because of its inexpensive computational cost, its implementation appears to be difficult as most of the standard deviation for FRP and the stable layer strength are extremely high, yielding crossover between the characterization of FRP and stable layer strength ranges of the different plume categories and therefore large uncertainty on the InjH estimation.

More recently Peterson et al. (2014) propose the idea of a model predicting the probability of injection above the PBL. Using an implementation of the Dozier (1981) algorithm based on MODIS input data, and 1028 boreal fire plumes extracted from the Northern American subset of the MISR data set, they show that the presence of plume in the troposphere can be independently related to the value of the classical FRP (Justice et al., 2002), fire size, FRP derived from the Dozier algorithm $\left(\mathrm{FRP}_{\mathrm{f}}\right)$, or the $\mathrm{FRP}_{\mathrm{f}}$ flux. By only showing a trend between fire characteristic variation and probability 


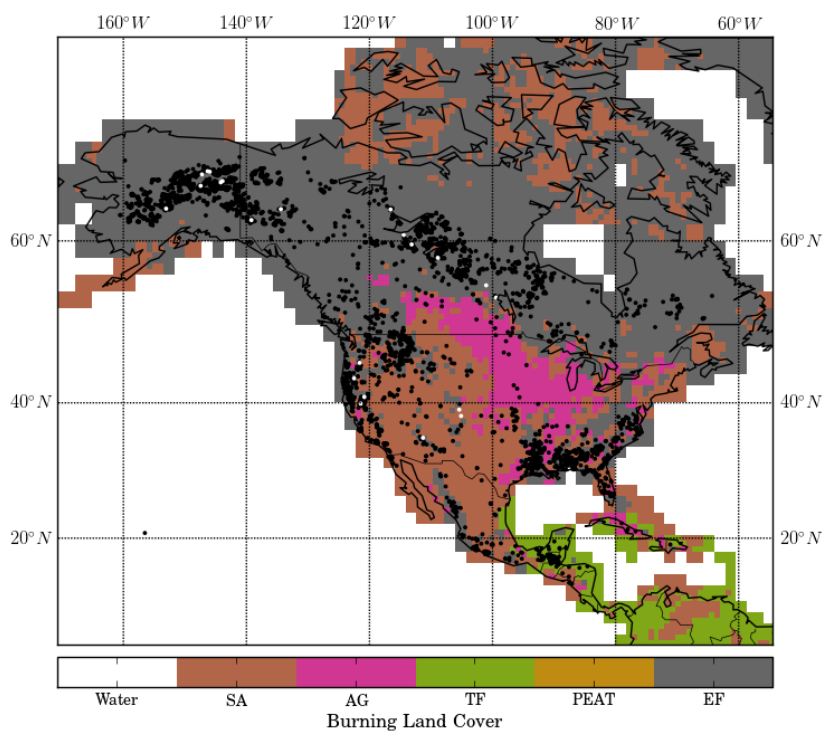

Figure 9. Fire locations contained within the Multi-angle Imaging SpectroRadiometer (MISR) plume height data set of Nelson et al. (2013) over North America for the time period 2001-2008 (black dots). White dots indicate the locations of the 22 fires plumes classed as having a plume height in excess of $4.5 \mathrm{~km}$. The map in the background shows the land cover used within the GFEDv3 biomass burning emissions inventory of van der Werf et al. (2010) where SA, AG, TF, PEAT, and EF stand for savannah, agriculture, tropical forest, peat land, and extra tropical forest respectively.

of injection in the troposphere, no real model is formulated and their conclusion highlights the potential importance of atmospheric stability in the plume rise (which they do not take into account).

To our knowledge, no statistically based models has already been implemented in CTMs. However, as their CPU cost would remain relatively low compared to any deterministic models, they show a great potential for implementation in large-scale model, in particular in climate model. However, their derivation is entirely relying on the good quality of their learning data set.

\section{Summary and conclusions}

Weakly burning landscape-scale fires appear to release their smoke mainly into the planetary boundary layer, but larger and/or more intensely burning wildfires produce smoke columns that can rise rapidly and semi-vertically above the source region, driven by the intense heat and convective energy released by the burning vegetation. These columns of hot smoke entrains cooler ambient air, developing into a rising plume within which the trace gases and aerosols are transported to potentially quite high altitudes, in the most extreme cases into the stratosphere. The characteristics of these rising plumes, and in particular the height that they reach before releasing the majority of the smoke burden,
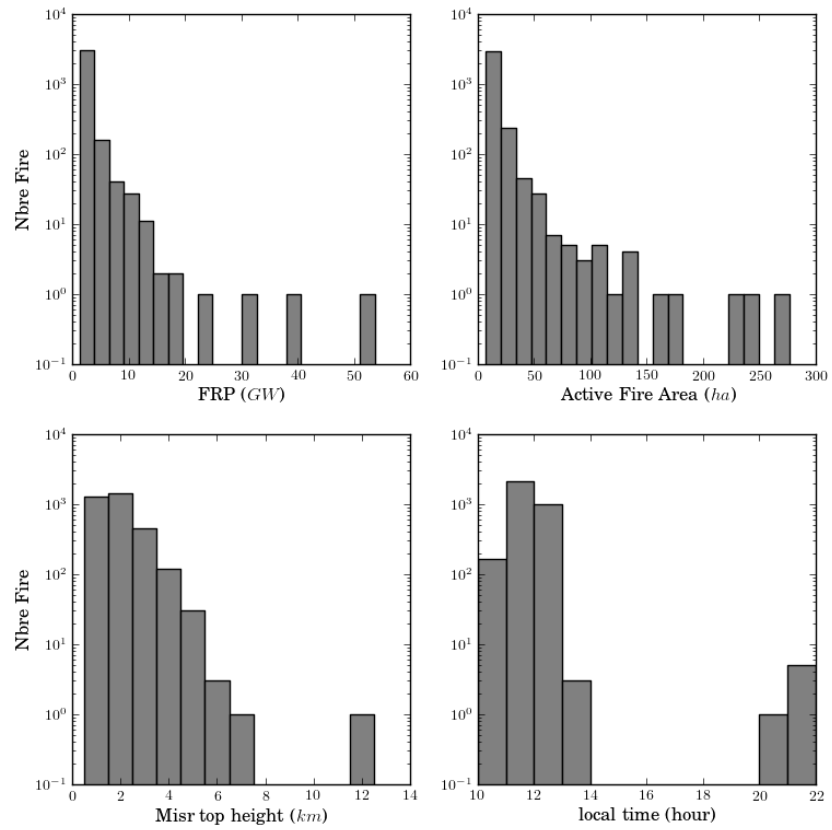

Figure 10. Distribution of FRP (a), active fire area (b), top plume height (c), and local time observation (d) for the 3320 fires of the current North American subset of the Multi-angle Imaging SpectroRadiometer (MISR) plume height project data set of Nelson et al. (2013) derived using the MINX tool shown in Fig. 4.

are now acknowledged as an important control on the atmospheric transport of emissions from certain of these larger fire events (Colarco et al., 2004; Turquety et al., 2007; Rio et al., 2010). However, results comparing model-based estimates of smoke plume rise parameter to actual plume height observations made from satellite EO instruments (e.g. Ichoku et al., 2012) do not yet provide a strong quantitative agreement (Val Martin et al., 2012). Furthermore, the degree of improvement given by actually including plume rise parameterizations in atmospheric chemistry transport models can be difficult to interpret due to the complex interactions with other atmospheric processes Chen et al. (2009).

Apart from simulations based on single fire events, where plume injection height is carefully prescribed (Damoah et al., 2006; Dirksen et al., 2009) or where highly detailed simulations are run at very high resolution (Trentmann et al., 2006), the impact of fire-induced up-draft on wildfire plume lofting appears, in general, to remain rather poorly understood and often weakly represented in current large-scale atmospheric modelling efforts. The impact of possibly coupled effects on ambient atmospheric processes, such as the convection induced by the nearby presence of a cold front, is also not well determined. At the scale of global CTMs, wildfire plume rise is generally represented by some form of parameterized model (Freitas et al., 2007; Rio et al., 2010; Sofiev et al., 2012). The ideal parameterization should account for the main physical processes responsible for the plume dy- 

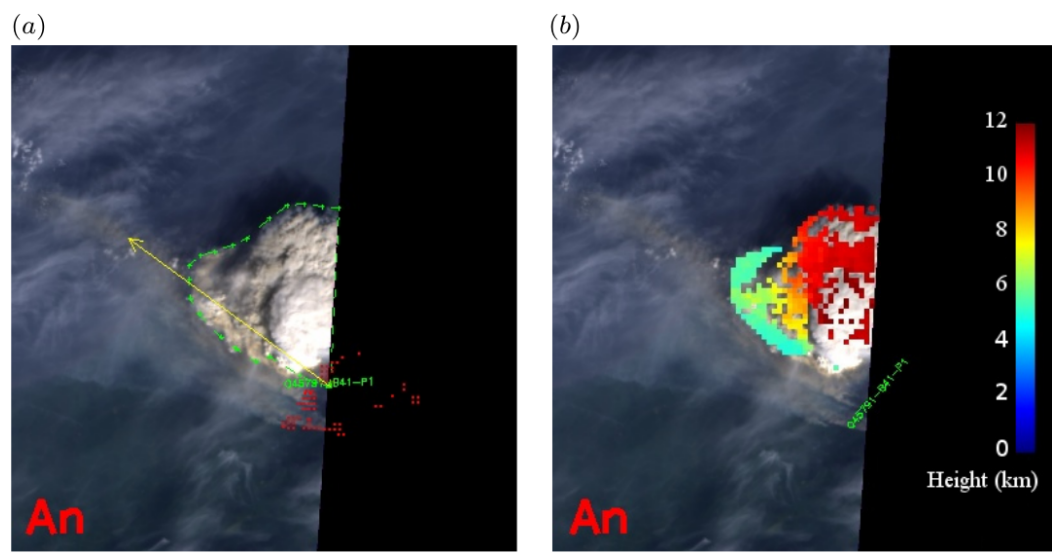

Figure 11. Overview of the highest fire plumes present in the current North American subset of the MISR plume height data set of Nelson et al. (2013), derived using the MINX tool shown in Fig. 4. The reference of this fire in the MISR data set is O45791-B41-P1, and it was observed in the Northwest Territories (Canada) on 27 July 2008. It shows the nadir image recorded by MISR, together with the plume contour set by the operator of the MINX software (a), the estimated wind direction (yellow arrow in a), and the stereo-height retrieval (b). Part of the image is black as the fire was located on the edge of the MISR swath. Images are taken from the MISR plume height project website (see footnote 1).

(a)

(b)

(c)

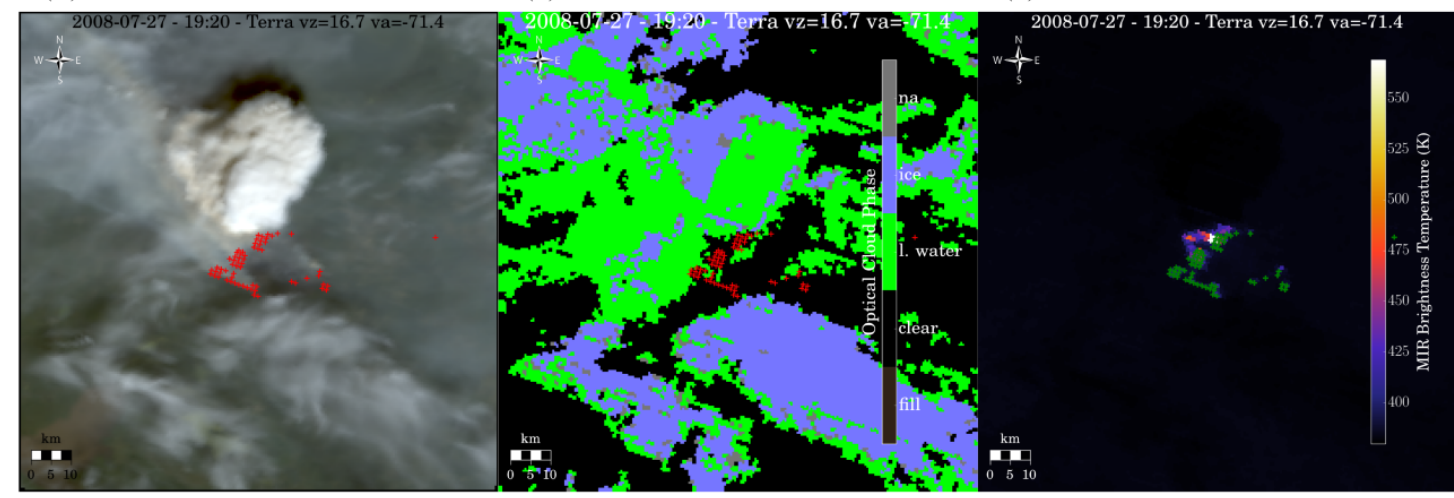

Figure 12. Images from the wider-swath Moderate Resolution Imaging Spectroradiometer (MODIS) for the same fire as in Fig. 11 at the same time. MODIS is mounted on the same Terra satellite as MISR (see Sect. 4.1). (a) is the false colour composite image of the area observed. (b) is the Middle Infra-Red brightness temperature. (c) is the optical cloud phase properties of the version 6 of the MODIS cloud product Platnick et al. (2003). Cross markers in (a) and (c) (red and green respectively) denote the location of MODIS pixels detected as containing active fire in the MODIS MOD14 active fire product of Giglio et al. (2003).

namics, using inputs regarding the fire characteristics that are available from EO satellites in near real time and with concurrent measurements of fire activity and plume height from single fire events available to validate the resulting system (and reduce any impact from larger-scale transport effects that influence comparisons of downwind plume characteristics).

Despite a demonstrated diurnal bias of MISR-derived plume heights towards lower plumes (Val Martin et al., 2010), the current MISR data set for North America counts 22 fires with plume top higher that $4.5 \mathrm{~km}$ (see Figs. 9 and 10 for an overview of the current MISR data over North America).
However, those high plumes might not be fully representative of standard fire behaviour as Fromm et al. (2010) show that PyroCb plume maturity peaks around 18:00, and no fires are observed around that time with MISR (see local time observation distribution in Fig. 10d). Therefore, any PyroCb contained within the MISR-derived plume height data set are certainly few in number, which leads to questions regarding the full representativeness of a random selection of fire events selected from this sample (Sofiev et al., 2012). In their approach, Val Martin et al. (2012) apply several selection criteria when taking a subsample of fires extracted from the MISR plume height data set for use in evaluation of their parameterized plume rise model, which is an adaptation of the widely used model of Freitas et al. (2007). However, even with this 
carefully selected evaluation data set, the validation of this PRM model fails to show very convincing results. Nevertheless, in future, such validation (or optimization) of plume rise models should continue to pay attention to the quality of the evaluation data sets, including the following questions.

i. Are the fire activity (FRP) and the plume dynamics (plume top height) linked? A time delay is necessary for the plume to dynamically adjust to change in the forcing induced by the energy release by the fire. For example, during the simulation of PyroCb of the Chisholm fire by the ATHAM model, it takes $40 \mathrm{~min}$ for the plume to reach its stationary altitude with a constant forcing (Trentmann et al., 2006). As the smoke plumes observed by MISR are more likely in a relatively early stage of development due to the morning overpass of the Terra satellite (see Sect. 4.1.2), the effect of this time lag might be even more important than if fires were randomly observed at any time of their development.

ii. Is the radiation of the fire affecting by absorption from the plume? In low ambient wind conditions, the fire plume is often located just above the fire and in case of large fires this might mask some of the fire-emitted radiation due to the thick aerosol layer causing significant scattering and/or absorption of the radiant energy, possibly causing underestimation of FRP and unreliable $\mathrm{CHF}$ and fire size retrievals using the Dozier algorithm. As an example, we note that the fire from the Northern American MISR plume height data set observed with the highest plume height of $12 \mathrm{~km}$ (see Fig. 10c) is reported to have a relatively low total FRP of $6 \mathrm{GW}$, when compare with the FRP distribution of the whole MISR data set (see Fig. 10a). The FRP is here determined as in Paugam et al. (2015): it is the FRP of the strongest cluster in the vicinity of the plume, in this case the top cluster in Fig. 12a. Figure 12b shows the optical cloud phase properties of the MODIS cloud product (Platnick et al., 2003) for this same fire. A large part of the plume is formed of ice, which lets us assume that we are in the presence of a PyroCb event. This means that the plume is formed of liquid water and ice particles that could be absorbing part of the MIR signal emitted by the fire. A close inspection of the MODIS MIR band (Fig. 12c) shows that in this particular event all high radiance pixels are outside the plume and that the fire detection algorithm of the MOD14 product misses a part of the fire front. This underestimation is even further accentuated in the official MISR data set as the plume contour set by the MINX operator includes only a part of the detected fire pixels (see Fig. 11). An even more extreme scenario is shown in Fig. 14 of Kahn et al. (2007), where no fire pixels were found for a high plume (marked P2 in their figure) which occurred in Québec on 6 July 2002. In these particularly extreme fire cases, it seems that fire pixels attached to the plume could be located under- neath it and remain undetected by the MODIS active fire product.

Despite these difficulties, the range of relevant data provided on actively burning fires and their smoke plumes by EO satellites continues to grow (e.g. Ichoku et al., 2012). For example, GOES-R (Schmit et al., 2005) and Himawari-8 (Kurino, 2012) will provide capabilities similar to MODIS, with a temporal frequency potentially as high as $30 \mathrm{~s}$, while Suomi NPP carrying VIIRS (Schroeder et al., 2014) and TET-1/BIRDS (Lorenz et al., 2012) will provide thermal bands with resolution up to $375 \mathrm{~m}$. This will allow for detailed observations of pyroconvection during peak burning hours. These improving capabilities, together with continuing advances in the extent to which plume rise models can be parameterized and incorporated into large-scale atmospheric CTMs (Peterson et al., 2014; Paugam et al., 2015), can be expected to continue to advance the accuracy of smoke plume injection estimates and the resulting impact on long-range atmospheric transport of these globally important emissions.

Acknowledgements. This study was supported by the NERC grant NE/E016863/1, by the NERC National Centre for Earth Observation (NCEO), and by the EU in the FP7 and $\mathrm{H} 2020$ projects MACC-II and MACC-III (contracts 283576 and 633080). The authors want also to thank M. Sofiev for sharing results from the implementation of his plume rise parameterization.

Edited by: R. Engelen

\section{References}

Achtemeier, G. L., Goodrick, S. A., Liu, Y., Garcia-Menendez, F., Hu, Y., and Odman, M. T.: Modeling Smoke PlumeRise and Dispersion from Southern United States Prescribed Burns with Daysmoke, Atmosphere, 2, 358-388, doi:10.3390/atmos2030358, 2011.

Amiridis, V., Giannakaki, E., Balis, D. S., Gerasopoulos, E., Pytharoulis, I., Zanis, P., Kazadzis, S., Melas, D., and Zerefos, C.: Smoke injection heights from agricultural burning in Eastern Europe as seen by CALIPSO, Atmos. Chem. Phys., 10, 1156711576, doi:10.5194/acp-10-11567-2010, 2010.

Andreae, M. O. and Merlet, P.: Emission of trace gases and aerosols from biomass burning, Global Biogeochem. Cy., 15, 955-966, doi:10.1029/2000GB001382, 2001.

Andreae, M. O., Rosenfeld, D., Artaxo, P., Costa, A. A., Frank, G. P., Longo, K. M., and Silva-Dias, M. A. F.: Smoking Rain Clouds over the Amazon, Science, 303, 1337-1342, doi:10.1126/science.1092779, 2004.

Bowman, D. M. J. S., Balch, J. K., Artaxo, P., Bond, W. J., Carlson, J. M., Cochrane, M. A., D’Antonio, C. M., DeFries, R. S., Doyle, J. C., Harrison, S. P., Johnston, F. H., Keeley, J. E., Krawchuk, M. A., Kull, C. A., Marston, J. B., Moritz, M. A., Prentice, I. C., Roos, C. I., Scott, A. C., Swetnam, T. W., van der Werf, G. R., and Pyne, S. J.: Fire in the Earth System, Science, 324, 481-484, doi:10.1126/science.1163886, 2009. 
Briggs, G. A.: Plume Rise Equations, in: Lectures on air pollution and environmental impact analyses, edited by: Haugen, D., AMS: Boston, MA, USA, 59-111, 1975.

Cammas, J.-P., Brioude, J., Chaboureau, J.-P., Duron, J., Mari, C., Mascart, P., Nédélec, P., Smit, H., Pätz, H.-W., Volz-Thomas, A., Stohl, A., and Fromm, M.: Injection in the lower stratosphere of biomass fire emissions followed by long-range transport: a MOZAIC case study, Atmos. Chem. Phys., 9, 5829-5846, doi:10.5194/acp-9-5829-2009, 2009.

Chatfield, R. B. and Delany, A. C.: Convection links biomass burning to increased tropical ozone: However, models will tend to overpredict O3, J. Geophysical Res.-Atmos., 95, 18473-18488, doi:10.1029/JD095iD11p18473, 1990.

Chédin, A., Serrar, S., Scott, N. A., Pierangelo, C., and Ciais, P.: Impact of tropical biomass burning emissions on the diurnal cycle of upper tropospheric $\mathrm{CO}_{2}$ retrieved from NOAA 10 satellite observations, J. Geophys. Res.-Atmos., 110, doi:10.1029/2004JD005540, 2005.

Chen, Y., Li, Q., Randerson, J. T., Lyons, E. A., Kahn, R. A., Nelson, D. L., and Diner, D. J.: The sensitivity of CO and aerosol transport to the temporal and vertical distribution of North American boreal fire emissions, Atmos. Chem. Phys., 9, 6559-6580, doi:10.5194/acp-9-6559-2009, 2009.

Coheur, P.-F., Clarisse, L., Turquety, S., Hurtmans, D., and Clerbaux, C.: IASI measurements of reactive trace species in biomass burning plumes, Atmos. Chem. Phys., 9, 5655-5667, doi:10.5194/acp-9-5655-2009, 2009.

Colarco, P. R., Schoeberl, M. R., Doddridge, B. G., Marufu, L. T., Torres, O., and Welton, E. J.: Transport of smoke from Canadian forest fires to the surface near Washington, D.C.: Injection height, entrainment, and optical properties, J. Geophys. Res.Atmos., 109, doi:10.1029/2003JD004248, 2004.

Damoah, R., Spichtinger, N., Servranckx, R., Fromm, M., Eloranta, E. W., Razenkov, I. A., James, P., Shulski, M., Forster, C., and Stohl, A.: A case study of pyro-convection using transport model and remote sensing data, Atmos. Chem. Phys., 6, 173185, doi:10.5194/acp-6-173-2006, 2006.

Dirksen, R. J., Folkert Boersma, K., de Laat, J., Stammes, P., van der Werf, G. R., Val Martin, M., and Kelder, H. M.: An aerosol boomerang: Rapid around-the-world transport of smoke from the December 2006 Australian forest fires observed from space, J. Geophys. Res.-Atmos., 114, D21201, doi:10.1029/2009JD012360, 2009.

Dozier, J.: A method for satellite identification of surface temperature fields of subpixel resolution, Remote Sens. Environ., 11, 221-229, doi:10.1016/0034-4257(81)90021-3, 1981.

ECMWF: IFS documentation Part IV: Physical Pro- cesses, Tech. Rep. CY38r1, European Center for Medium-Range Weather Forecasts, Shinfield Park, Reading, UK, available at: http: //old.ecmwf.int/research/ifsdocs/CY38r1/IFSPart4.pdf (last access: March 2015), 2012.

Elguindi, N., Clark, H., Ordóñez, C., Thouret, V., Flemming, J., Stein, O., Huijnen, V., Moinat, P., Inness, A., Peuch, V.-H., Stohl, A., Turquety, S., Athier, G., Cammas, J.-P., and Schultz, M.: Current status of the ability of the GEMS/MACC models to reproduce the tropospheric $\mathrm{CO}$ vertical distribution as measured by MOZAIC, Geosci. Model Dev., 3, 501-518, doi:10.5194/gmd-3501-2010, 2010.
Fisher, D., Muller, J.-P., and Yershov, V.: Automated Stereo Retrieval of Smoke Plume Injection Heights and Retrieval of Smoke Plume Masks From AATSR and Their Assessment With CALIPSO and MISR, Geoscience and Remote Sens., 52, 12491258, doi:10.1109/TGRS.2013.2249073, 2014.

Freeborn, P. H., Wooster, M. J., Hao, W. M., Ryan, C. A., Nordgren, B. L., Baker, S. P., and Ichoku, C.: Relationships between energy release, fuel mass loss, and trace gas and aerosol emissions during laboratory biomass fires, J. Geophys. Res.-Atmos/, 113, D01301, doi:10.1029/2007JD008679, 2008.

Freitas, S. R., Longo, K. M., and Andreae, M. O.: Impact of including the plume rise of vegetation fires in numerical simulations of associated atmospheric pollutants, Geophys. Res. Lett., 33, doi:10.1029/2006g1026608, 2006.

Freitas, S. R., Longo, K. M., Chatfield, R., Latham, D., Silva Dias, M. A. F., Andreae, M. O., Prins, E., Santos, J. C., Gielow, R., and Carvalho Jr., J. A.: Including the sub-grid scale plume rise of vegetation fires in low resolution atmospheric transport models, Atmos. Chem. Phys., 7, 3385-3398, doi:10.5194/acp-7-3385-2007, 2007.

Freitas, S. R., Longo, K. M., Silva Dias, M. A. F., Chatfield, R., Silva Dias, P., Artaxo, P., Andreae, M. O., Grell, G., Rodrigues, L. F., Fazenda, A., and Panetta, J.: The Coupled Aerosol and Tracer Transport model to the Brazilian developments on the Regional Atmospheric Modeling System (CATT-BRAMS) - Part 1: Model description and evaluation, Atmos. Chem. Phys., 9, 28432861, doi:10.5194/acp-9-2843-2009, 2009.

Freitas, S. R., Longo, K. M., Trentmann, J., and Latham, D.: Technical Note: Sensitivity of 1-D smoke plume rise models to the inclusion of environmental wind drag, Atmos. Chem. Phys., 10, 585-594, doi:10.5194/acp-10-585-2010, 2010.

Fromm, M., Bevilacqua, R., Servranckx, R., Rosen, J., Thayer, J. P., Herman, J., and Larko, D.: Pyro-cumulonimbus injection of smoke to the stratosphere: Observations and impact of a super blowup in northwestern Canada on 3-4 August 1998, J. Geophys. Res.-Atmos., 110, D08205, doi:10.1029/2004JD005350, 2005.

Fromm, M., Lindsey, D. T., Servranckx, R., Yue, G., Trickl, T., Sica, R., Doucet, P., and Godin-Beekmann, S.: The Untold Story of Pyrocumulonimbus, B. Am. Meteorol. Soc., 91, 1193-1209, doi:10.1175/2010BAMS3004.1, 2010.

Fromm, M. D. and Servranckx, R.: Transport of forest fire smoke above the tropopause by supercell convection, Geophys. Res. Lett., 30, doi:10.1029/2002GL016820, 2003.

Giglio, L. and Kendall, J. D.: Application of the Dozier retrieval to wildfire characterization: a sensitivity analysis, Remote Sens. Environ., 77, 34-49, doi:10.1016/S0034-4257(01)001924, 2001.

Giglio, L. and Schroeder, W.: A global feasibility assessment of the bi-spectral fire temperature and area retrieval using $\{$ MODIS $\}$ data, Remote Sens. Environ., 152, 166-173, doi:10.1016/j.rse.2014.06.010, 2014.

Giglio, L., Descloitres, J., Justice, C. O., and Kaufman, Y. J.: An Enhanced Contextual Fire Detection Algorithm for \{MODIS \}, Remote Sens. Environ., 87, 273-282, doi:10.1016/S00344257(03)00184-6, 2003.

Giglio, L., Csiszar, I., and Justice, C. O.: Global distribution and seasonality of active fires as observed with the Terra and Aqua Moderate Resolution Imaging Spectroradiometer (MODIS) sensors, J. Geophys. Res., 111, doi:10.1029/2005jg000142, 2006. 
Gonzi, S. and Palmer, P. I.: Vertical transport of surface fire emissions observed from space, J. Geophys. Res.-Atmos., 115, D02306, doi:10.1029/2009JD012053, 2010.

Gonzi, S., Palmer, P. I., Paugam, R., Wooster, M., and Deeter, M. N.: Quantifying pyroconvective injection heights using observations of fire energy: sensitivity of spaceborne observations of carbon monoxide, Atmos. Chem. Phys., 15, 4339-4355, doi:10.5194/acp-15-4339-2015, 2015.

Goodrick, S. L., Achtemeier, G. L., Larkin, N. K., Liu, Y., and Strand, T. M.: Modelling smoke transport from wildland fires: a review, Int. J. Wildland Fire, 22, 83-94, 10.1071/WF11116, 2013.

Grell, G., Freitas, S. R., Stuefer, M., and Fast, J.: Inclusion of biomass burning in WRF-Chem: impact of wildfires on weather forecasts, Atmos. Chem. Phys., 11, 5289-5303, doi:10.5194/acp11-5289-2011, 2011.

Guan, H., Esswein, R., Lopez, J., Bergstrom, R., Warnock, A., Follette-Cook, M., Fromm, M., and Iraci, L. T.: A multi-decadal history of biomass burning plume heights identified using aerosol index measurements, Atmos. Chem. Phys., 10, 6461-6469, doi:10.5194/acp-10-6461-2010, 2010.

Hodzic, A., Madronich, S., Bohn, B., Massie, S., Menut, L., and Wiedinmyer, C.: Wildfire particulate matter in Europe during summer 2003: meso-scale modeling of smoke emissions, transport and radiative effects, Atmos. Chem. Phys., 7, 4043-4064, doi:10.5194/acp-7-4043-2007, 2007.

Hyer, E. J. and Chew, B. N.: Aerosol transport model evaluation of an extreme smoke episode in Southeast Asia, Atmos. Environ., 44, 1422-1427, doi:10.1016/j.atmosenv.2010.01.043, 2010.

Ichoku, C. and Ellison, L.: Global top-down smoke-aerosol emissions estimation using satellite fire radiative power measurements, Atmos. Chem. Phys., 14, 6643-6667, doi:10.5194/acp14-6643-2014, 2014.

Ichoku, C., Kahn, R., and Chin, M.: Satellite contributions to the quantitative characterization of biomass burning for climate modeling, Atmos. Res., 111, 1-28, doi:10.1016/j.atmosres.2012.03.007, 2012.

Jian, Y. and Fu, T.-M.: Injection heights of springtime biomassburning plumes over peninsular Southeast Asia and their impacts on long-range pollutant transport, Atmos. Chem. Phys., 14, 3977-3989, doi:10.5194/acp-14-3977-2014, 2014.

Johnson, B. T., Osborne, S. R., Haywood, J. M., and Harrison, M. A. J.: Aircraft measurements of biomass burning aerosol over West Africa during DABEX, J. Geophys. Res.-Atmos., 113, D00C06, doi:10.1029/2007JD009451, 2008.

Justice, C., Giglio, L., Korontzi, S., Owens, J., Morisette, J., Roy, D., Descloitres, J., Alleaume, S., Petitcolin, F., and Kaufman, Y.: The \{MODIS $\}$ fire products the Moderate Resolution Imaging Spectroradiometer (MODIS): a new generation of Land Surface Monitoring, Remote Sens. Environ., 83, 244-262, doi:10.1016/S0034-4257(02)00076-7, 2002.

Kahn, R. A., Li, W.-H., Moroney, C., Diner, D. J., Martonchik, J. V., and Fishbein, E.: Aerosol source plume physical characteristics from space-based multiangle imaging, J. Geophys. Res.-Atmos., 112, D11205, doi:10.1029/2006JD007647, 2007.

Kahn, R. A., Chen, Y., Nelson, D. L., Leung, F.-Y., Li, Q., Diner, D. J., and Logan, J. A.: Wildfire smoke injection heights: Two perspectives from space, Geophys. Res. Lett., 35, doi:10.1029/2007GL032165, 2008.
Kaiser, J. W., Heil, A., Andreae, M. O., Benedetti, A., Chubarova, N., Jones, L., Morcrette, J.-J., Razinger, M., Schultz, M. G., Suttie, M., and van der Werf, G. R.: Biomass burning emissions estimated with a global fire assimilation system based on observed fire radiative power, Biogeosciences, 9, 527-554, doi:10.5194/bg-9-527-2012, 2012.

Kaskaoutis, D., Kharol, S. K., Sifakis, N., Nastos, P., Sharma, A. R., Badarinath, K., and Kambezidis, H.: Satellite monitoring of the biomass-burning aerosols during the wildfires of August 2007 in Greece: Climate implications, Atmos. Environ., 45, 716-726, doi:10.1016/j.atmosenv.2010.09.043, 2011.

Keeley, J. E.: Fire intensity, fire severity and burn severity: a brief review and suggested usage, Int. J. Wildland Fire, 18, 116-126, doi:10.1071/wf07049, 2009.

Kukkonen, J., Nikmo, J., Sofiev, M., Riikonen, K., Petäjä, T., Virkkula, A., Levula, J., Schobesberger, S., and Webber, D. M.: Applicability of an integrated plume rise model for the dispersion from wild-land fires, Geosci. Model Dev., 7, 2663-2681, doi:10.5194/gmd-7-2663-2014, 2014.

Kurino, T.: Future Plan and Recent Activities for the Japanese Follow-on Geostationary Meteorological Satellite Himawari-8/9, AGU Fall Meeting Abstracts, p. 3, 2012.

Labonne, M., Bréon, F.-M., and Chevallier, F.: Injection height of biomass burning aerosols as seen from a spaceborne lidar, Geophys. Res. Lett., 34, doi:10.1029/2007GL029311, 2007.

Latham, D.: PLUMP: A one-dimensional plume predictor and cloud model for fire and smoke managers, Tech. Rep. INT-GTR-314, Intermountain Research Station, USDA Forest Service, 1994.

Leung, F.-Y. T., Logan, J. A., Park, R., Hyer, E., Kasischke, E., Streets, D., and Yurganov, L.: Impacts of enhanced biomass burning in the boreal forests in 1998 on tropospheric chemistry and the sensitivity of model results to the injection height of emissions, J. Geophys. Res.-Atmos., 112, D10313, doi:10.1029/2006JD008132, 2007.

Longo, K. M., Freitas, S. R., Andreae, M. O., Setzer, A., Prins, E., and Artaxo, P.: The Coupled Aerosol and Tracer Transport model to the Brazilian developments on the Regional Atmospheric Modeling System (CATT-BRAMS) - Part 2: Model sensitivity to the biomass burning inventories, Atmos. Chem. Phys., 10, 5785-5795, doi:10.5194/acp-10-5785-2010, 2010.

Lorenz, E., Hoffmann, A., Oertel, D., Tiemann, J., and Halle, W.: Upcoming and prospective fire monitoring missions based on the heritage of the BIRD (bi-spectral infrared detection) satellite, in: Geoscience and Remote Sensing Symposium (IGARSS), 2012 IEEE International, 225-228, doi:10.1109/IGARSS.2012.6351597, 2012.

Luderer, G., Trentmann, J., Winterrath, T., Textor, C., Herzog, M., Graf, H. F., and Andreae, M. O.: Modeling of biomass smoke injection into the lower stratosphere by a large forest fire (Part II): sensitivity studies, Atmos. Chem. Phys., 6, 5261-5277, doi:10.5194/acp-6-5261-2006, 2006.

Mazzoni, D., Logan, J. A., Diner, D., Kahn, R., Tong, L., and Li, Q.: A data-mining approach to associating $\{$ MISR $\}$ smoke plume heights with \{MODIS \} fire measurements, Remote Sens. Environ., 107, 138-148, doi:10.1016/j.rse.2006.08.014, 2007.

McCarter, R. J. and Broido, A.: Radiative and convective energy from wood crib fires, Pyrodynamics, 2, 65-85, 1965.

Mims, S., Kahn, R., Moroney, C., Gaitley, B., Nelson, D., and Garay, M.: MISR Stereo Heights of Grassland Fire Smoke 
Plumes in Australia, IEEE Trans. Geosci. Remote Sens., 48, 2535, doi:10.1109/tgrs.2009.2027114, 2010.

Nelson, D. L., Garay, M. J., Kahn, R. A., and Dunst, B. A.: Stereoscopic Height and Wind Retrievals for Aerosol Plumes with the MISR INteractive eXplorer (MINX), Remote Sens., 5, 45934628, doi:doi:10.3390/rs5094593, 2013.

Paugam, R., Paoli, R., and Cariolle, D.: Influence of vortex dynamics and atmospheric turbulence on the early evolution of a contrail, Atmos. Chem. Phys., 10, 3933-3952, doi:10.5194/acp-103933-2010, 2010.

Paugam, R., Wooster, M., Atherton, J., Freitas, S. R., Schultz, M. G., and Kaiser, J. W.: Development and optimization of a wildfire plume rise model based on remote sensing data inputs - Part 2, Atmos. Chem. Phys. Discuss., 15, 9815-9895, doi:10.5194/acpd-15-9815-2015, 2015.

Peterson, D. and Wang, J.: A sub-pixel-based calculation of fire radiative power from \{MODIS $\}$ observations: 2 . Sensitivity analysis and potential fire weather application, Remote Sens. Environ., 129, 231-249, doi:10.1016/j.rse.2012.10.020, 2013.

Peterson, D., Wang, J., Ichoku, C., Hyer, E., and Ambrosia, V.: A sub-pixel-based calculation of fire radiative power from \{MODIS \} observations: 1: Algorithm development and initial assessment, Remote Sens. Environ., 129, 262-279, doi:10.1016/j.rse.2012.10.036, 2013.

Peterson, D., Hyer, E., and Wang, J.: Quantifying the potential for high-altitude smoke injection in the North American boreal forest using the standard MODIS fire products and subpixelbased methods, J. Geophys. Res.-Atmos., 119, 3401-3419, doi:10.1002/2013JD021067, 2014.

Peterson, D. A., Hyer, E. J., Campbell, J. R., Fromm, M. D., Hair, J. W., Butler, C. F., and Fenn, M. A.: The 2013 Rim Fire: Implications for Predicting Extreme Fire Spread, Pyroconvection, and Smoke Emissions, B. Am. Meteorol. Soc., 96, 229-247, doi:10.1175/bams-d-14-00060.1, 2015.

Pfister, G. G., Wiedinmyer, C., and Emmons, L. K.: Impacts of the fall 2007 California wildfires on surface ozone: Integrating local observations with global model simulations, Geophys. Res. Lett., 35, doi:10.1029/2008GL034747, 2008.

Pfister, G. G., Avise, J., Wiedinmyer, C., Edwards, D. P., Emmons, L. K., Diskin, G. D., Podolske, J., and Wisthaler, A.: CO source contribution analysis for California during ARCTAS-CARB, Atmos. Chem. Phys., 11, 7515-7532, doi:10.5194/acp-11-75152011, 2011.

Platnick, S., King, M., Ackerman, S., Menzel, W., Baum, B., Riedi, J., and Frey, R.: The MODIS cloud products: algorithms and examples from Terra, Geosci. Remote Sens., 41, 459-473, doi:10.1109/TGRS.2002.808301, 2003.

Prata, A., Cechet, R., Barton, I., and Llewellyn-Jones, D.: The along track scanning radiometer for ERS-1-scan geometry and data simulation, IEEE Trans. Geosci. Remote Sens., 28, 3-13, doi:10.1109/36.45741, 1990.

Prins, E. M., Feltz, J. M., Menzel, W. P., and Ward, D. E.: An overview of GOES-8 diurnal fire and smoke results for SCAR-B and 1995 fire season in South America, J. Geophys. Res.-Atmos., 103, 31821-31835, doi:10.1029/98JD01720, 1998.

Raffuse, S. M., Craig, K. J., Larkin, N. K., Strand, T. T., Sullivan, D. C., Wheeler, N. J. M., and Solomon, R.: An Evaluation of Modeled Plume Injection Height with Satellite-
Derived Observed Plume Height, Atmosphere, 3, 103-123, doi:10.3390/atmos3010103, 2012.

Reid, J., Hyer, E., Prins, E., Westphal, D., Zhang, J., Wang, J., Christopher, S., Curtis, C., Schmidt, C., Eleuterio, D., Richardson, K., and Hoffman, J.: Global Monitoring and Forecasting of Biomass-Burning Smoke: Description of and Lessons From the Fire Locating and Modeling of Burning Emissions (FLAMBE) Program, Selected Topics in Applied Earth Observations and Remote Sensing, 2, 144-162, doi:10.1109/JSTARS.2009.2027443, 2009.

Reutter, P., Trentmann, J., Seifert, A., Neis, P., Su, H., Chang, D., Herzog, M., Wernli, H., Andreae, M. O., and Pöschl, U.: 3$\mathrm{D}$ model simulations of dynamical and microphysical interactions in pyroconvective clouds under idealized conditions, Atmos. Chem. Phys., 14, 7573-7583, doi:10.5194/acp-14-75732014, 2014..

Rio, C., Hourdin, F., and Chédin, A.: Numerical simulation of tropospheric injection of biomass burning products by pyro-thermal plumes, Atmos. Chem. Phys., 10, 3463-3478, doi:10.5194/acp10-3463-2010, 2010.

Roberts, G. and Wooster, M.: Fire Detection and Fire Characterization Over Africa Using Meteosat SEVIRI, IEEE Trans. Geosci. Remote Sens., 46, 1200-1218, doi:10.1109/tgrs.2008.915751, 2008.

Roberts, G., Wooster, M. J., and Lagoudakis, E.: Annual and diurnal african biomass burning temporal dynamics, Biogeosciences, 6 , 849-866, doi:10.5194/bg-6-849-2009, 2009.

Ross, A. N., Wooster, M. J., Boesch, H., and Parker, R.: First satellite measurements of carbon dioxide and methane emission ratios in wildfire plumes, Geophys. Res. Lett., 40, 4098-4102, doi:10.1002/grl.50733, 2013.

Schmit, T. J., Gunshor, M. M., Menzel, W. P., Gurka, J. J., Li, J., and Bachmeier, A. S.: INTRODUCING THE NEXT-GENERATION ADVANCED BASELINE IMAGER ON GOES-R, B. Am. Meteorol. Soc., 86, 1079-1096, doi:10.1175/bams-86-8-1079, 2005.

Schroeder, W., Oliva, P., Giglio, L., and Csiszar, I. A.: The New \{VIIRS $375 \mathrm{~m}$ active fire detection data product: Algorithm description and initial assessment, Remote Sens. Environ., 143, 8596, doi:10.1016/j.rse.2013.12.008, 2014.

Sessions, W. R., Fuelberg, H. E., Kahn, R. A., and Winker, D. M.: An investigation of methods for injecting emissions from boreal wildfires using WRF-Chem during ARCTAS, Atmos. Chem. Phys., 11, 5719-5744, doi:10.5194/acp-11-5719-2011, 2011.

Sestak, M., O’Neill, S., Ferguson, S., Ching, J., and Fox, D.: Integration of Wildfire Emissions into Models-3/Cmaq with the Prototypes: Community Smoke Emissions Modeling System (CSEM) and BLUESKY, Models-3 User's Workshop, 21-23 October, EPA, Research Triangle Park, NC, USA, 2002.

Sharples, J. J.: An overview of mountain meteorological effects relevant to fire behaviour and bushfire risk, Int. J. Wildland Fire, 18, 737-754, doi:10.1071/wf08041, 2009.

Sofiev, M., Ermakova, T., and Vankevich, R.: Evaluation of the smoke-injection height from wild-land fires using remote-sensing data, Atmos. Chem. Phys., 12, 1995-2006, doi:10.5194/acp-12-1995-2012, 2012.

Sofiev, M., Vankevich, R., Ermakova, T., and Hakkarainen, J.: Global mapping of maximum emission heights and resulting vertical profiles of wildfire emissions, Atmos. Chem. Phys., 13, 7039-7052, doi:10.5194/acp-13-7039-2013, 2013. 
Strada, S., Mari, C., Filippi, J.-B., and Bosseur, F.: Wildfire and the atmosphere: Modelling the chemical and dynamic interactions at the regional scale, Atmos. Environ., 51, 234-249, doi:10.1016/j.atmosenv.2012.01.023, 2012.

Toon, O. B., Turco, R. P., Robock, A., Bardeen, C., Oman, L., and Stenchikov, G. L.: Atmospheric effects and societal consequences of regional scale nuclear conflicts and acts of individual nuclear terrorism, Atmos. Chem. Phys., 7, 1973-2002, doi:10.5194/acp-7-1973-2007, 2007.

Tosca, M. G., Randerson, J. T., Zender, C. S., Nelson, D. L., Diner, D. J., and Logan, J. A.: Dynamics of fire plumes and smoke clouds associated with peat and deforestation fires in Indonesia, J. Geophys. Res.-Atmos., 116, D08207, doi:10.1029/2010JD015148, 2011.

Trentmann, J., Luderer, G., Winterrath, T., Fromm, M. D., Servranckx, R., Textor, C., Herzog, M., Graf, H.-F., and Andreae, M. O.: Modeling of biomass smoke injection into the lower stratosphere by a large forest fire (Part I): reference simulation, Atmos. Chem. Phys., 6, 5247-5260, doi:10.5194/acp-65247-2006, 2006.

Turquety, S., Logan, J. A., Jacob, D. J., Hudman, R. C., Leung, F. Y., Heald, C. L., Yantosca, R. M., Wu, S., Emmons, L. K., Edwards, D. P., and Sachse, G. W.: Inventory of boreal fire emissions for North America in 2004: Importance of peat burning and pyroconvective injection, J. Geophys. Res.-Atmos., 112, D12S03, doi:10.1029/2006JD007281, 2007.

Val Martin, M., Logan, J. A., Kahn, R. A., Leung, F.-Y., Nelson, D. L., and Diner, D. J.: Smoke injection heights from fires in North America: analysis of 5 years of satellite observations, Atmos. Chem. Phys., 10, 1491-1510, doi:10.5194/acp-10-14912010, 2010.

Val Martin, M., Kahn, R. A., Logan, J. A., Paugam, R., Wooster, M., and Ichoku, C.: Space-based observational constraints for 1D fire smoke plume-rise models, J. Geophys. Res.-Atmos., 117, D22204, doi:10.1029/2012JD018370, 2012.

Val Martin, M., Heald, C. L., Ford, B., Prenni, A. J., and Wiedinmyer, C.: A decadal satellite analysis of the origins and impacts of smoke in Colorado, Atmos. Chem. Phys., 13, 74297439, doi:10.5194/acp-13-7429-2013, 2013.

van der Werf, G. R., Randerson, J. T., Giglio, L., Collatz, G. J., Mu, M., Kasibhatla, P. S., Morton, D. C., DeFries, R. S., Jin, Y., and van Leeuwen, T. T.: Global fire emissions and the contribution of deforestation, savanna, forest, agricultural, and peat fires (19972009), Atmos. Chem. Phys., 10, 11707-11735, doi:10.5194/acp10-11707-2010, 2010.
Viegas, D. X.: Convective processes in forest fires, in: Buoyant Convection in Geophysical Flows, Kluwer Academic Publishers, AA Dordrecht, The Netherlands, 401-420, 1998.

Ward, D. S., Kloster, S., Mahowald, N. M., Rogers, B. M., Randerson, J. T., and Hess, P. G.: The changing radiative forcing of fires: global model estimates for past, present and future, Atmos. Chem. Phys., 12, 10857-10886, doi:10.5194/acp12-10857-2012, 2012.

Wiedinmyer, C., Akagi, S. K., Yokelson, R. J., Emmons, L. K., AlSaadi, J. A., Orlando, J. J., and Soja, A. J.: The Fire INventory from NCAR (FINN): a high resolution global model to estimate the emissions from open burning, Geosci. Model Dev., 4, 625641, doi:10.5194/gmd-4-625-2011, 2011.

Woods, A. W.: The dynamics of explosive volcanic eruptions, Rev. Geophys., 33, 495-530, doi:10.1029/95RG02096, 1995.

Wooster, M. J., Roberts, G., Perry, G. L. W., and Kaufman, Y. J.: Retrieval of biomass combustion rates and totals from fire radiative power observations: FRP derivation and calibration relationships between biomass consumption and fire radiative energy release, J. Geophys. Res.-Atmos., 110, D24311, doi:10.1029/2005JD006318, 2005.

Wooster, M. J., Xu, W., and Nightingale, T.: Sentinel-3 SLSTR active fire detection and FRP product: Pre-launch algorithm development and performance evaluation using MODIS and ASTER datasets, Remote Sens. Environ., 120, 236-254, doi:10.1016/j.rse.2011.09.033, 2012a.

Wooster, M. J., Perry, G. L. W., and Zoumas, A.: Fire, drought and El Niño relationships on Borneo (Southeast Asia) in the pre-MODIS era (1980-2000), Biogeosciences, 9, 317-340, doi:10.5194/bg-9-317-2012, 2012b.

$\mathrm{Xu}$, W., Wooster, M., Roberts, G., and Freeborn, P.: New GOES imager algorithms for cloud and active fire detection and fire radiative power assessment across North, South and Central America, Remote Sens. Environ., 114, 1876-1895, doi:10.1016/j.rse.2010.03.012, 2010.

Zhukov, B., Lorenz, E., Oertel, D., Wooster, M., and Roberts, G.: Spaceborne detection and characterization of fires during the bi-spectral infrared detection (BIRD) experimental small satellite mission (2001-2004), Remote Sens. Environ., 100, 29-51, doi:10.1016/j.rse.2005.09.019, 2006. 